\title{
8. Auftakt zum Vorgehen gegen West-Berlin
}

\section{Chruschtschows Entschluß zu einer neuen Berlin-Initiative}

1960 hatte sich die wirtschaftliche Lage der DDR außerordentlich verschlechtert. Aus dem mäßigen Aufschwung 1958 war eine heftige Krise geworden. Die in einer Sechs-Wochen-Kampagne erzwungene Vollkollektivierung der Landwirtschaft hatte katastrophale Folgen. Die Agrarerzeugung erreichte einen Tiefstand, weil große Viehbestände geschlachtet wurden und viele Felder brachlagen. Um die schlimmsten Nöte zu überwinden, sah sich die Regierung genötigt, ungeachtet knapper Mittel die Investitionen um 30\% aufzustocken. Die Weizenimporte mußten stark ausgeweitet werden. Die Zahl der bäuerlichen Flüchtlinge nahm dramatisch zu. Die Hochkonjunktur in der Bundesrepublik trug dazu bei, daß auch andere Bevölkerungsgruppen in den Westen gingen. Der Exodus erreichte ein bedrohliches Ausmaß. Das - von Chruschtschow für entscheidend erachtete Kräfteverhältnis im Systemwettstreit der zwei deutschen Staaten wurde dadurch noch ungünstiger. ${ }^{1}$ Schon im Sommer 1960 zeigte sich Ulbricht sehr besorgt. Ihm war bewußt, daß die Lage Adenauer politisch stärkte und die Chance zerstörte, die Bevölkerung von der Überlegenheit des Sozialismus zu überzeugen. ${ }^{2}$

Als die Kündigung des Handelsabkommens durch Bonn die völlige Abhängigkeit der DDR von den westdeutschen Lieferungen deutlich machte, erkannte er den ganzen Umfang der Misere und kam zu dem Schluß, es müsse unbedingt etwas unternommen werden. Nur wenn sich der Kreml zum Abschluß des Friedensvertrages und zur Durchsetzung der Freistadtregelung bereit finde, seien die Probleme der DDR zu lösen. In Moskau sah man die Dinge gelassener, doch war man auch dort über die Entwicklung besorgt, zumal sich in der Bundesrepublik ebenfalls ein ungünstiger Trend abzeichnete. Die SPD konnte bei den bevorstehenden Bundestagswahlen kaum auf eine Mehrheit hoffen und hatte mit dem Godesberger Programm die „sozialistische Alternative“ zu Adenauers Politik endgültig fallen lassen. Man tröstete sich jedoch damit, daß diese veränderte Haltung in der westdeutschen Arbeiterklasse „Unzufriedenheit auslösen“ müsse. ${ }^{3}$

Am 30. November 1960 verlangte Ulbricht von Chruschtschow „Klarheit über die Perspektiven des Kampfes um den Friedensvertrag und die Lösung der Westberlin-Frage“. Dieser antwortete, die seit dem Ultimatum vor zwei Jahren verflossene Zeit sei nicht verloren, denn seither seien die „Positionen der imperialisti-

1 Otčët o rabote Posolstva v GDR za 1960 god (Bericht an Ju.V. Andropov), 15. 12. 1960, RGANI, 5, 49, 287 (rolik 8948), B1. 63-68.

2 Gespräch M. G. Pervuchin - W. Ulbricht, 15. 7. 1960, RGANI, 5, 49, 288, Bl. 232-237.

3 Botschafter Pervuchin im Gespräch mit dem ungarischen Botschafter in Ost-Berlin: István Rostás an Károlyi Kiss/Imre Hollai (ungar.), 25. 4. 1961, MOL 288.f.32/1961/12.ö.e., Bl. 163. 
schen Gegner erschüttert" ", 4 und erklärte es für nachteilig, wenn die DDR die Lage verschärfen würde, indem sie sich von den Beschränkungen ihrer Souveränität zu befreien suche. Um nicht im Westen als wortbrüchig zu gelten (gegenüber dem er 1959 und 1960 den Willen zum Einvernehmen bekundet hatte), wolle er die Situation bis zum Gipfeltreffen unverändert lassen. Erst wenn dann keine Einigung über Friedensvertrag oder Interimsabkommen erzielt werde, womit freilich zu rechnen sei, könne er an einen Separatvertrag denken. Damit stelle sich die Frage nach dem Zeitpunkt. Solle das 1961 geschehen? Ulbricht verneinte und rief damit die erstaunte Gegenfrage hervor: Warum? Die Antwort lautete, dazu fehle doch der Mut. Das wollte Chruschtschow nicht auf sich sitzen lassen und legte dar, man müsse jetzt unbedingt handeln, wenn man nicht großen Ansehensverlust erleiden und die Position der Gegenseite stärken wolle. Zudem sei die Lage günstig. Der Westen werde weder eine wirtschaftliche Blockade verhängen noch gar einen Krieg beginnen. Dennoch sollten auch dafür Vorkehrungen getroffen werden. Die DDR müsse vor den Folgen etwaiger Sanktionen geschützt und von der ökonomischen Westabhängigkeit befreit werden. Erneut mahnte Chruschtschow, vor Abschluß des Friedensvertrages keine einseitigen Schritte zu unternehmen. ${ }^{5}$

Das Politbüro der SED befaßte sich am 4. und 10. Januar 1961 ausführlich mit der Lage in der DDR. Sorge bereiteten vor allem die wirtschaftlichen Schwierigkeiten und die unvergleichlich besseren Lebensbedingungen in der Bundesrepublik. Die anschwellende „Republikflucht“ schien bedrohlich. Bruno Leuschner und Heinrich Rau erklärten, wegen der Abhängigkeit vom Außenhandel und von den westdeutschen Lieferungen sei man in einem Teufelskreis gefangen, der sich auch mit der Hilfe der UdSSR und der anderen Verbündeten nicht durchbrechen lasse. Leuschner zog den Schluß, der Lebensstandard müsse den „materiellen Bedingungen“ entsprechen. Das werde die Versorgung verschlechtern mit der Folge, daß die Neigung zum Verlassen der DDR weiter zunehmen würde. Als Ausweg aus dem Dilemma bezeichnete Rau den baldigen Abschluß des Friedensvertrages. Damit könne man nicht bis zu einer Gipfelkonferenz warten. Es wurden ein Brief Ulbrichts an Chruschtschow und die Einsetzung einer Arbeitsgruppe beschlossen, die „Vorschläge zur entschiedenen Eindämmung“ der Massenflucht vorlegen sollte. ${ }^{6}$

Aufgrund der Quellenlage muß offen bleiben, ob man dabei bereits an eine mögliche Schließung der Sektorengrenze dachte. Nach der - freilich keinesfalls zuverlässigen ${ }^{7}$ - Erinnerung des damaligen Kulturministers soll im Februar unter der Leitung des Parteichefs in engem Kreis über Details der Abriegelung West-

\footnotetext{
Aktenvermerk über Unterredung Ulbrichts mit N. S. Chruščëv, 30. 11. 1960, SAPMO-BArch, DY 30/3566, B1. 82.

5 Sowjetisches Protokoll des Gesprächs Chruščëv - Ulbricht, 30. 11. 1960, in engl. Übersetzung wiedergegeben bei Hope M. Harrison, Ulbricht and the Concrete „Rose“: New Archival Evidence on the Dynamics of Soviet-East German Relations and the Berlin Crisis, 1958-1961, Working Paper No. 5, Cold War International History Project, Woodrow Wilson International Center for Scholars, Washington/DC, Mai 1993, Anhang A.

6 Wilfriede Otto, 13. August 1961 - eine Zäsur in der europäischen Nachkriegsgeschichte, in: Beiträge zur Geschichte der Arbeiterbewegung, 1/1997, S. 48; Anlage 1 zum Protokoll der Sitzung des Politbüros der SED Nr. 2 vom 10. 1. 1961, SAPMO-BArch, DY 30/J IV 2/2A 797, Bl. 28.

7 Vgl. seine auf Erinnerungen gestützte Darstellung des Volksaufstands in der DDR 1953: Hans Bentzien, Was geschah am 17. Juni? Vorgeschichte, Verlauf, Hintergründe, Berlin 2003.
} 
Berlins beraten worden sein. ${ }^{8}$ Sicher ist, daß sich die SED-Führung und das sowjetische Oberkommando in der DDR zunehmend auf eine kritische Situation im Innern und gegenüber den Westmächten einstellten. Ulbricht fragte seinen Verteidigungsminister Hoffmann bereits im Januar, inwieweit die UdSSR bei inneren Unruhen militärisch eingreifen würde und ob sie ein ständig einsatzfähiges Sperrsystem an der Grenze zur Bundesrepublik für erforderlich halte. ${ }^{9}$ Demnach galt seine Aufmerksamkeit einem eventuellen militärischen Konflikt mit Schwerpunkt im Westen. Nach Abschluß des separaten Friedensvertrages und die daraufhin geplante Übernahme der Kontrolle über den West-Berliner Zugangsverkehr durch die DDR würden die Westmächte mutmaßlich mit einer bewaffneten Aktion vom Boden der Bundesrepublik aus reagieren. Wie dann die Truppen der UdSSR am besten einzusetzen seien, besprachen Hoffmann, der sowjetische Oberbefehlshaber in Deutschland, Armeegeneral Jakubowskij, und der Oberkommandierende der Warschauer-Pakt-Streitkräfte, Marschall Gretschko, am 10. Februar miteinander. ${ }^{10}$

Die inneren Probleme der DDR setzten der Fähigkeit zur Konfrontation Grenzen, verstärkten aber auch den Handlungsdruck. Aussagen westlicher Akteure (deren Ansichten jedoch vielfach nicht den amtlichen Standpunkt zum Ausdruck brachten ${ }^{11}$ ) ließen Chruschtschow vermuten, daß sich unter den Westmächten und sogar in der Bundesrepublik ein Haltungswandel in seinem Sinne abzeichne. Das wertete er als „gewaltigen Erfolg“, der zu großer Hoffnung berechtige. ${ }^{12}$ Der Führungswechsel in Washington schien die Durchsetzung seiner Ziele zu begünstigen. Der Kremlchef sah sich nicht nur der Verlegenheit enthoben, mit Eisenhower einem Präsidenten gegenüberzustehen, den er im Mai 1960 rundweg als Gesprächspartner abgelehnt hatte. Zum Nachfolger war nicht dessen Vize Richard Nixon, der seit seinem Besuch in Moskau vom Juni 195913 dort als kompromißloser „Kalter Krieger“ galt ${ }^{14}$, sondern John F. Kennedy gewählt worden. Chruschtschow, der den Wahlkampf intensiv verfolgt hatte, war tief befriedigt und setzte seine Hoffnungen auf den neuen Mann im Weißen Haus. ${ }^{15}$

8 Hans Bentzien, Meine Sekretäre und ich, Berlin 1995, S. 172-174, zitiert nach Armin Wagner, Walter Ulbricht und die geheime Sicherheitspolitik der SED. Der Nationale Verteidigungsrat der DDR und seine Vorgeschichte (1953-1971), Berlin 2002, S. 441.

9 W. Ulbricht an Armeegeneral Hoffmann, 21. 1. 1961, BArch-MArch, AZN 32612, Bl. 72-75.

10 Niederschrift über eine Beratung im MfNV, 10. 2. 1961, BArch-MArch, DVW-1/18771, Bl. 25-29.

11 Das galt insbesondere für die Auffassungen des westdeutschen Botschafters in Moskau, Hans Kroll.

12 Sowjetisches Protokoll des Gesprächs zwischen N. S. Chruščëv und W. Ulbricht, 30. 11. 1960, in: H. Harrison, Ulbricht, a.a.O., Anhang A.

13 Hierzu: Extract from Conversation between N. S. Khrushchev and Mr. R. Nixon on the 26t July 1959, Document 01574, Annex No. 1, The Berlin Crisis, 1958-1962. Documents from the National Security Archive, microfiches published by Chadwyck-Healey Inc.

14 Wladislaw Subok/Konstantin Pleschakow, Der Kreml im Kalten Krieg. Von 1945 bis zur Kubakrise, Hildesheim 1997, S. 333; V. M. Suchodrev, Jazyk moj - drug moj. Ot Chruščëva do Gorbačëva, Moskau 1999, S. 133. Vgl. auch zwei Anlagen zum Schreiben von G. Žukov an das ZK der KPdSU, 20. 8. 1959, RGANI, 5, 30, 305 (rolik 4619), Bl. 36: Spravka o pravitel'stvennom apparate SŠA po vedeniju „psichologičeskoj vojny protiv stran socializma, ebd., Bl. 49; Spravka o peredačach radiostancii "Golos Ameriki“ i tak nazyvaemych „častnych“ radiostancij, veščajuščich v Sovetskij Sojuz, ebd., Bl. 58.

15 V. Suchodrev, a.a.O., S. 133; W. Subok/K. Pleschakow, a.a.O., S. 333 f. 


\section{Einschätzung des Wechsels an der Spitze der USA}

Ein politisches Porträt, das Chruschtschow im August 1960 zugegangen war, stellte Kennedy als Pragmatiker dar, der frühe Festlegungen scheute und Mitte der fünfziger Jahre Distanz zur antikommunistischen Kampagne McCarthys gewahrt hatte. Beides erschien positiv. Dagegen wurde dem neuen Präsidenten eine widersprüchliche Haltung attestiert. Er sehe das Ost-West-Verhältnis als ständigen Kampf und hege Mißtrauen gegenüber der UdSSR, trete aber grundsätzlich für Verhandlungen ein und kritisiere, daß die USA keine konkreten Abrüstungsvorschläge unterbreitet hätten. Er wende sich jedoch freilich gegen ein Gipfeltreffen mit der Sowjetunion, solange die Amerikaner ihre verlorene „Position der Stärke“ nicht wiederhergestellt hätten. Hinsichtlich Berlins vertrete er die Ansicht, daß man lieber einen Nuklearkrieg beginnen als die Stadt aufgeben solle, denn damit würde man zugleich aus Deutschland und Europa hinausgedrückt werden. Kennedy sei zwar bereit, den Vereinten Nationen eine Rolle in der Stadt zuzugestehen, wolle das aber nicht als Ersatz für die westliche Präsenz akzeptieren. Ähnlich inkonsistent erschien seine Haltung im Blick auf die kommunistischen Länder Osteuropas: Er halte zwar die „Befreiungspolitik“ der alten Administration für unrealistisch und gescheitert, erkenne aber die Unwiderruflichkeit der dortigen Systemveränderungen nicht an und suche die Rückkehr zur alten Ordnung mit Mitteln flexibler Einflußnahme, vor allem wirtschaftlicher Hilfe, zu fördern. ${ }^{16}$

Solcher Bedenken ungeachtet, hielt Chruschtschow die Wahl Kennedys im November 1960 für insgesamt erfreulich. Er sei weit weniger hart als Nixon. Das lasse bei künftigen Verhandlungen „normale und vorteilhafte Bedingungen“ erwarten. Die „neue Karte müsse man auszuspielen suchen“. ${ }^{17}$ Noch wichtiger scheint gewesen zu sein, daß man es nicht mit dem Parteigänger Eisenhowers zu tun hatte, der zudem im Kreml unangenehm aufgefallen war. Der Umstand, daß im Weißen Haus künftig ein anderer zu bestimmen hatte, ließ darauf hoffen, daß sich ein Ausweg aus der verfahrenen Lage gegenüber den USA eröffnete. ${ }^{18}$ Auch wenn es dafür keine konkreten Anhaltspunkte gab, schien der Wechsel in Washington Aussicht auf Verständigung in sowjetischem Sinne zu bieten. ${ }^{19}$ Der Amtsantritt eines Präsidenten, der als Verkörperung einer neuen Zeit galt, schien zudem Chruschtschows optimistische Erwartung zu bestätigen, daß der „Fortschritt“ das Alte besiege, was in seiner Sicht mit einer allmählichen Entwicklung zum Sozialismus gleichbedeutend war. Der sowjetische Parteichef meinte, das Votum der amerikanischen Wähler gegen Nixon beruhe vor allem auf wachsender Einsicht in die Notwendigkeit, sich auf ein die UdSSR immer stärker begünstigendes Kräfteverhältnis einzustellen und daher die eigene Außenpolitik grundlegend zu ändern.

Positiv wurde im Kreml aufgenommen, daß sich Kennedy noch vor der Amtsübernahme um einen direkten Informationskanal bemühte. Beim ersten Kontakt

16 „A Typical Pragmatist“: The Soviet Embassy Profiles. John F. Kennedy, 1960, in: Cold War International History Project Bulletin, Heft 4 (Herbst 1994), S. 64-67.

17 Zusammenfassung des politischen Berichts der Botschaft der VRP in Moskau für die Zeit vom 1. 7.-31. 12. 1960 (poln.), o.D., AAN, KC PZPR XI A/78, Bl. 436.

18 William Taubman, Khrushchev. The Man and his Era, New York-London 2003, S. 485 f.

19 Oleg Trojanovskij, Čerez gody i rasstojanija. Istorija odnoj sem’i, Moskau 1997, S. 233. 
mit dem als Vermittler vorgesehenen KGB-Offizier am 1. Dezember 1960 legte der Bruder des künftigen Präsidenten, Robert, dar, wie Politik gegenüber der UdSSR aussehen solle. Nach der Aufzeichnung des sowjetischen Gesprächspartners, die erwartungsgemäß dem Kremlchef sofort zugeleitet wurde, wollte der kommende Mann im Weißen Haus den Beziehungen zur UdSSR vorrangige Aufmerksamkeit widmen. Diese könnten und sollten sich in den nächsten Jahren verbessern. Besonderen Wert wolle man auf Fragen der Abrüstung legen. Auch beabsichtige man ein Gipfeltreffen mit Chruschtschow, zu dem man ein besseres Verhältnis herzustellen hoffe als bisher. $\mathrm{Zu}$ einer solchen Begegnung werde es freilich nur kommen, wenn es keine Zweifel an positiven Ergebnissen gebe. Der Präsident werde dazu noch nicht in den ersten vier Monaten bereit sein, denn er müsse zuvor sein innenpolitisches Programm dem Kongreß vorlegen. Über die Lage in Berlin sei er sehr besorgt und wolle sich um eine Regelung des Problems bemühen. Falls die UdSSR jedoch bald Druck ausübe, werde er mit Sicherheit die Position des Westens verteidigen. Die Frage des wechselseitigen Handelsaustauschs wolle er erst später behandeln. Nach erzielter Übereinkunft werde es leichter sein, diesen Knäuel zu entwirren. Zum Abschluß erfolgte der Hinweis, daß man die Beziehungen nicht zur UdSSR, sondern zu China als das grundlegende Problem der kommenden Jahre ansehe. ${ }^{20}$

Das Interesse der neuen Administration an baldigen Vereinbarungen und ihre Bereitschaft, die Regelung der offenen Fragen nicht weiter zu verzögern, schienen zu großen Hoffnungen zu berechtigen. Der Kreml hielt ein Zwischenabkommen auf der Basis seiner Genfer Vorschläge für möglich oder gar wahrscheinlich. Vielleicht brauchte man daher gar nicht erst zur Androhung des separaten Friedensvertrags mit der DDR zu greifen und konnte so der Konfrontation mit den USA entgehen. Auch andere Informationen wurden in diesem Sinne verstanden. Chruschtschow erhielt die Mitteilung, der neue Präsident sei nach dem internen Urteil eines engen Beraters zwar „hartnäckig und beharrlich“, aber zugleich ein Mann, der politische Fragen „nicht vom Standpunkt allgemeiner Urteile, sondern von den konkreten Bedingungen der Realität aus“ betrachte. Er schien demnach zu flexiblem - und damit potentiell nachgiebigem - Handeln disponiert. Dennoch war klar, daß seine Ansichten über einen möglichen Kompromiß stark von den sowjetischen Vorstellungen abwichen. Wie man dem Kremlchef aufgrund von Einblicken in inneramerikanische Überlegungen berichtete, dachte Kennedy an ein Abkommen über Deutschland, das wegen der strittigen Frage der Vereinigung keine endgültige Regelung sein könne. Zudem wolle er als Preis für die Hinnahme der Teilung und die Anerkennung der Oder-Neiße-Linie die Garantie eines freien Zugangs nach West-Berlin fordern. ${ }^{21}$ Das stellte den Kreml nicht zufrieden, galt aber als gewaltiger Fortschritt gegenüber der Position von Dulles, der weitere Konzessionen erhoffen ließ.

20 In engl. Übersetzung wiedergegeben bei Aleksandr Fursenko/Timothy Naftali, „One Hell of a Gamble“. Khrushchev, Castro, and Kennedy, 1958-1964, New York-London 1997, S. $81 \mathrm{f}$.

21 P. Abrasimov an N. S. Chruščëv, 8. 2. 1961, RGANI, 5, 30, 365 (rolik 4632), Bl. 25 f. 


\section{Einschätzung der internationalen Lage und vorbereitende Gespräche mit den Amerikanern}

Chruschtschow glaubte zudem, daß die Konstellation im westlichen Bündnis die Durchsetzung seiner Ziele begünstige. Schon 1958 hatte Macmillan große Zugeständnisse in Deutschland und Berlin befürwortet. Ein Problem aus sowjetischer Sicht war dagegen de Gaulle, der überhaupt nicht unter Druck verhandeln wollte. Hoffnung wurde jedoch daraus geschöpft, daß sich der französische Staatspräsident klar gegen die deutsche Einheit wende und damit den „Bonner Revanchismus" ablehne. Intern äußerte sich Chruschtschow über ihn stets mit großer Wärme. Die sich schon 1960 abzeichnende Annäherung Frankreichs an die Bundesrepublik hielt er für einen momentanen Flirt de Gaulles mit Adenauer, der nicht von Dauer sein werde. Ende 1960 scheint er daran aber Zweifel bekommen zu haben: Er ließ sich von seinen Mitarbeitern nicht mehr auf das Verhältnis zwischen Bonn und Paris ansprechen.22 Chruschtschow bekundete frühzeitig sein Interesse an einem Treffen mit Kennedy, um die „Überreste des Zweiten Weltkriegs" rasch zu liquidieren. Dabei erklärte er sich wie in den beiden Vorjahren zu Zwischenlösungen bereit, wenn sich das Ziel auf diese Weise leichter erreichen lasse. ${ }^{23}$ Der amerikanische Präsident ließ ihm jedoch sagen, er müsse sich erst einmal einarbeiten. ${ }^{24}$ Erst in einer Mitteilung, die er Chruschtschow am 9. März durch Botschafter Thompson aushändigen ließ, schlug er eine persönliche Begegnung vor, die an einem neutralen Ort stattfinden solle. ${ }^{25}$

Der sowjetische Parteichef stimmte sogleich zu und benutzte die Gelegenheit zu einem ersten Meinungsaustausch. Dabei gewann er den Eindruck, die USA wollten die Deutschland-Frage nicht in die Erörterung der strittigen Fragen einbeziehen. Das war nicht in seinem Sinne. Er erklärte daher, dieses Problem sei für Europa und die ganze Welt von großer Bedeutung, und hob hervor, er werde diesen Standpunkt nicht ändern. Es sei notwendig, den als Ergebnis des Zweiten Weltkriegs eingetretenen Veränderungen rechtliche Form zu geben. Deswegen solle ein Friedensvertrag mit den zwei deutschen Staaten geschlossen werden. Man wolle zwar die Wiedervereinigung auf beiden Seiten, doch böten deren gegensätzliche Vorstellungen keine Aussicht darauf. Wenn man versuchen wollte, die jeweiligen Ziele durchzusetzen, würde das den dritten Weltkrieg bedeuten. Thompsons Hinweis, die USA hätten „bestimmte Verpflichtungen gegenüber der Bevölkerung West-Berlins“, beantwortete Chruschtschow mit dem gewohnten

22 Zusammenfassung des politischen Berichts der Botschaft der VRP in Moskau für die Zeit vom 1. 7.-31. 12. 1960 (poln.), AAN, KC PZPR XI A/78, Bl. 436.

23 N. S. Chruščëv an J. F. Kennedy, o.D. [Chruščëv am 17.1. 1961 zur Unterschrift zugeleitet], AVPRF, 0129, 45, 329, 11, Bl. 7-23; G. M. Kornienko, Upuščënnaja vozmožnost'. Vstreča N. S. Chruščëva i Dž. Kennedi v Vene v 1961g., in: Novaja i novejšaja istorija, 2/1992, S. 97.

24 Spravka. O besede posla SSSR v SŠA t. Men’šikov s licami iz bližajšego okruženii Kennedi, 8. 2. 1961, AVPRF, 0129, 45, 329, 11, Bl. 37, 39; Information [für die Parteiführung der ČSR] über Sondierungsgespräche des sowjetischen Botschafters in Washington, o.D. [Jan./Feb. 1961], in: Michal Reiman/Petr Luňák (Hrsg.), Studená válka 1954-1964. Sovětské dokumenty v českých archivech, Brünn 2000, S. 166-169.

25 J. F. Kennedy an N. S. Chruščëv, 22. 2. 1961, in: Foreign Relations of the United States [hinfort: FRUS], 1961-1963, Bd. VI, S. 5-7. 
Argument, der Freistadtstatus gewährleiste den Verzicht auf auswärtige Einmischung in die inneren Angelegenheiten.26 Mit einem raschen Einlenken der Amerikaner konnte er demnach nicht rechnen. ${ }^{27}$ Er appellierte daraufhin an diese, die Beziehungen zur UdSSR zu verbessern, mit ihr vorsichtigen Umgang zu pflegen und alle Handlungen zu unterlassen, aus denen sich „Komplikationen“ ergeben könnten. ${ }^{28}$

\section{Meinungsaustausch zwischen Chruschtschow und Ulbricht}

Obwohl Chruschtschow am 30. November 1960 die Absicht bekundet hatte, den Abschluß des Friedensvertrags und die Freistadtregelung für West-Berlin voranzutreiben, war Ulbricht weiterhin skeptisch. Würde der sowjetische Führer wirklich bei seinem Wort bleiben? Nach aller bisherigen Erfahrung war das keineswegs sicher. Sowjetische Hinweise, man müsse abwarten, bis Kennedy Zeit zu den erforderlichen Vorbereitungen gehabt habe und zu Verhandlungen bereit sei, dürften den Zweifel verstärkt haben. Daher ließ der SED-Chef im Außenministerium der DDR ein Papier über die „Möglichkeiten des taktischen Vorgehens in der Frage des Friedensvertrags und Westberlins“ ausarbeiten. Darin sollten keine endgültigen Positionen formuliert werden. Es ging vielmehr darum, die internationale Diskussion wieder in Gang zu bringen. ${ }^{29}$

Gestützt auf diese Vorlage und eine Diskussion des Politbüros darüber, ${ }^{30}$ appellierte Ulbricht am 19. Januar 1961 an Chruschtschow, im begonnenen Jahr „wenigstens einen Teil der Reste des Krieges in Westberlin und in Deutschland abzubauen. "Die Voraussetzungen dafür seien „günstig, da die Adenauer-Regierung in der Zeit der [bevorstehenden] Bundestagswahlkampagne nicht an einer Zuspitzung der Lage interessiert ist und Präsident Kennedy im ersten Jahr seiner Präsidentschaft ebenfalls keine Verschärfung der Lage wünscht.“ Diese Zeit solle genutzt werden, um vollendete Tatsachen zu schaffen. Das Schreiben enthielt die bisherigen Forderungen mit der Einschränkung, die westlichen Truppen in Berlin brauchten vorerst nur verringert zu werden und der Militärverkehr über die Zugangswege könne bis zum vollständigen Abzug in eineinhalb bis zwei Jahren respektiert werden. Zunächst könnten auch weitere „Reste des Krieges“ fortbeste-

26 L. Thompson an Department of State, 10.3. 1961, in: FRUS, 1961-1963, Bd. V (Internet-Ausgabe), Dokument 42; Zapis' besedy N.S. Chruščëva s poslom SŠA v SSSR L. Tompsonom 9 marta 1961 goda, g. Novosibirsk, SAPMO-BArch, DY 30/3663, Bl. 1-21/MOL, 288.f. 9/1961/3.ö.e., B1. 132-152.

27 Das bestätigte sich erneut in einer Unterredung zwischen Kennedy und Gromyko am 27. 3. 1961 (Zapis' besedy A. A. Gromyko s prezidentom SŠA D. Kennedi 27 marta 1961 goda, MOL, 288.f. 9/1961/3.ö.e., Bl. 167-176).

28 Entwurf des sowjetischen Außenministeriums für eine Antwort Chruščëvs an Kennedy, o.D. [Mitte März 1961], AVPRF, 0129, 45, 329, 11, Bl. 55-58; Zapis' besedy A. A. Gromyko s prezidentom SŠA D. Kennedi 27 marta 1961 goda, Vašington, AVPRF, 0129, 45, 329, 11, Bl. 63-72.

29 O. Winzer an W. Ulbricht (mit beigefügter Ausarbeitung), 10.1. 1961, SAPMO-BArch, DY 30/ 3508, Bl. 1-20.

30 Aufzeichnung ohne Überschrift [Ulbricht über die Diskussion im SED-Politbüro nach seinem Bericht zu den Fragen des Friedensvertrags und West-Berlins], 16. 1. 1961, SAPMO-BArch, DY 30/3508, B1. 37-46. 
hen, die erst „bei den Verhandlungen über die Vorbereitung eines Friedensvertrages behandelt" werden würden. Gingen die Westmächte auf diesen „Kompromiß“ nicht ein, würde es „unvermeidlich“ werden, daß die UdSSR und andere dazu bereite Staaten einen Friedensvertrag mit der DDR ohne ihre Beteiligung abschlössen. Als Vorbereitung für diese Eventualität sollte nach Ulbrichts Ansicht das Politische Konsultativkomitee des Warschauer Pakts einberufen werden. ${ }^{31}$

Chruschtschow antwortete mit der Versicherung, daß er zur Vereinbarung vom 30. November des Vorjahres stehe. Er erklärte sich mit den Erwägungen über Maßnahmen zur „Liquidierung der Überreste des Krieges“ und zur „Normalisierung der Lage in West-Berlin“" einverstanden, und akzeptierte, daß notfalls ein separater Friedensschluß mit der DDR erforderlich werde. Hinter der - breit ausgeführten - Zustimmung verbarg sich jedoch eine abwehrende Tendenz. Ulbricht wurde nachdrücklich darauf hingewiesen, daß die UdSSR die vorgesehenen Schritte bereits eingeleitet habe. Die Sondierungen brauchten jedoch Zeit. Erst wenn die Haltung Kennedys klarer geworden sei, könne man beurteilen, ob ein Einvernehmen möglich sei. Auch mußte sich der ungeduldige ostdeutsche Parteichef vorhalten lassen, die sozialistischen Länder hätten „bereits nicht wenig erreicht“. Die "militaristische Position der Regierung der BRD und der sie unterstützenden Westmächte“ sei „entlarvt“ worden. Dadurch sei es „gelungen, ihre Position in der deutschen Frage in gewissem Ausmaß zu erschüttern." Auch habe sich die „internationale Autorität“ der DDR erhöht. „Die geschickte Ausnutzung dieser von uns gemeinsam errungenen Vorteile kann weitere Früchte in dieser Hinsicht bringen.“ Damit verband sich die Warnung vor „offenen einseitigen Akten von unserer Seite“. Diese könnten „von gewissen Kreisen in den USA“ dazu benutzt werden, Kennedy zu drängen, Standpunkte nach der Art Eisenhowers zu beziehen, „was der BRD und den reaktionären Kreisen im Westen zustatten käme.“32

Chruschtschow stimmte ungenannten Maßnahmen zu, die Ulbricht brieflich angeregt habe. Diese seien „unter gewissen Umständen [...] vollkommen notwendig", falls es zu keiner Übereinkunft mit Kennedy komme. Sie müßten absprachegemäß bei Abschluß des Separatfriedensvertrags durchgeführt werden. Um was es sich dabei handelte, ist wegen fehlender Quellen unklar. Karl-Heinz Schmidt vermutet, das könnte sich auf einen Vorschlag zum Bau der Berliner Mauer bezogen haben. ${ }^{33}$ Davon ist jedoch in keinem der - anscheinend vollständig überlieferten Schreiben des SED-Chefs die Rede. Zudem leuchtet nicht ein, daß dieser auf Schließung der Grenze in Berlin gedrungen und daß Chruschtschow dem zugestimmt haben soll. Der sowjetische Führer hatte sich stets gegen dortige Abriegelungsmaßnahmen gewehrt. Der Annahme, Ulbricht habe ihn durch bloße briefliche Anregung davon abgebracht, steht auch entgegen, daß der ostdeutsche Parteichef die Sache Ende März im Warschauer Pakt zum Thema machen wollte. Hätte

31 W. Ulbricht an N. S. Chruščëv, 18. [recte: 19.] 1. 1961, SAPMO-BArch, DY 30/3508, Bl. 59-66.

32 N. S. Chruščëv an W. Ulbricht, 30. 1. 1961, AVPRF, 0742, 6, 46, 34, Bl. 3-5. In den Fassungen, die im früheren Zentralen Parteiarchiv der SED aufbewahrt werden, fehlen die kritischen Passagen: SAPMO-BArch, DY 30/3508, Bl. 122f. (russ.), 114-116 (dte. Übers.).

33 Karl-Heinz Schmidt, Dialog über Deutschland. Studien zur Deutschlandpolitik von KPdSU und SED (1960-1979), Baden-Baden 1998, S. 49-52. 
Chruschtschow ihn darin bereits unterstützt, wäre kein Bemühen darum mehr erforderlich gewesen. Vermutlich bezog sich der sowjetische Führer auf den Brief des SED-Chefs vom 19. Januar, in dem um Wirtschafts- und Finanzhilfe zur Stabilisierung der DDR, vor allem zur Abwendung der Zahlungsunfähigkeit, ersucht worden war. Das Anliegen war gemäß übereinstimmender Vorstellung damit begründet worden, es sei unerläßlich, die - bisher noch von westdeutschen Lieferungen abhängige - DDR ökonomisch standfest $\mathrm{zu}$ machen. Andernfalls sei zu befürchten, daß eine Konfrontation wegen Berlin zu einer innenpolitischen Katastrophe führe. ${ }^{34}$

\section{Beratungen im Warschauer Pakt}

Chruschtschow war nicht auf Ulbrichts Ersuchen eingegangen, eine Tagung des Politischen Konsultativkomitees über Friedensvertrag und Freistadtregelung einzuberufen. Statt dessen hatte er ein bilaterales Treffen vorgeschlagen. ${ }^{35} \mathrm{Zwar}$ sah er auch eine Beratung der östlichen Parteichefs vor, doch sollte sich diese nicht mit Deutschland- und Berlin-Fragen befassen. Als Thema wurde die militärische Stärkung des Warschauer Pakts vorgesehen. ${ }^{36}$ Damit nahm Chruschtschow einen fundamentalen Kurswechsel vor. Noch Anfang 1960 hatte er nach früheren Truppenreduzierungen eine weitere Verringerung von 1,2 Millionen Mann dekretiert und erklärt, die „Verfechter des ,kalten Krieges“" seien durch die Wirtschaftskraft der UdSSR in eine schwierige Lage gebracht und würden durch Friedens- und Abrüstungsinitiativen zusätzlich in die Enge getrieben. ${ }^{37}$ Nunmehr war die Hoffnung verflogen, man könne die Westmächte allein durch nuklearstrategische Macht (deren Aufbau zudem weit hinter den großspurigen Erklärungen des Kreml zurückblieb) zum Nachgeben zwingen. Daher erschien es notwendig, daß die sozialistischen Staaten eine überlegene Fähigkeit zur Kriegführung auf dem europäischen Schauplatz glaubhaft machten. ${ }^{38}$

Auch Ulbricht hielt das für richtig, war aber darüber hinaus an einem Beschluß interessiert, der eine „Normalisierung“ der Lage in West-Berlin versprach. Wenn Chruschtschow, wie er nach wie vor argwöhnte, es nicht auf einen akuten Konflikt mit dem Westen ankommen lassen wollte, dann sollte wenigstens zunächst einmal auf andere Weise Abhilfe für die DDR geschaffen werden. Am 16. März 1961 sprach Ulbricht in der SED-Führung das Problem der anschwellenden Massenflucht an und stellte die Frage, ob man nicht die Sektorengrenze schließen müsse. ${ }^{39}$ Welcher innerstaatlichen Lage er sich gegenübersah, erläuterte er Perwuchin am 20. März. Die DDR leide unter akutem Mangel an Rohstoffen wie Ar-

\footnotetext{
Ulbricht an Chruščëv, 19. 1. 1961, SAPMO-BArch, DY 30/3508, Bl. 59-73.

N. S. Chruščëv an W. Ulbricht, 30. 1. 1961, AVPRF, 0742, 6, 46, 34, Bl. 5.

36 N. S. Chruščëv an W. Ulbricht, 24. 1. 1961, SAPMO-BArch, DY 30/3386 Bl. 118f. (russ.), $116 \mathrm{f}$. (dte. Übers.); N.S. Chruščëv an W. Ulbricht, 15. 3. 1961, SAPMO-BArch, DY 30/3386, Bl. $122 \mathrm{f}$.

37 N. S. Chruščëv an W. Ulbricht, 6. 1. 1960, SAPMO-BArch, DY 30/3507, Bl. 1-6.

38 Sergej A. Kondrašëv, Über die Mauer, deren Grundlage und den [sic] Urteil der Völker, Vortragspapier, vorgelegt auf der Internationalen DDR-Forschertagung in der Europäischen Akademie Otzenhausen, 8.-11. 11. 2001, S. 5.

39 So nach Peter Wyden, „Wir machen Berlin dicht“, in: Der Spiegel, 41/1989, S. 161.
} 
beitskräften, und die Außenhandelsbilanz weise ein großes Defizit auf. Er kündigte Maßnahmen gegen diejenigen Bürger seines Staates an, die in West-Berlin arbeiteten. Das werde großen Lärm im Westen hervorrufen, doch das mache ihm nichts aus. Wenn Leute weggingen, die ihre Kraft nicht für die DDR einsetzten, verliere man nichts. Wie der Botschafter dem Moskauer Außenministerium berichtete, hielt er die Darstellung der Schwierigkeiten für „etwas übertrieben“.40

Auf der Tagung des Politischen Konsultativkomitees der Warschauer-PaktStaaten am 28./29. März 1961 hielt sich Ulbricht nicht an das militärische Thema und lenkte die Aufmerksamkeit der versammelten Parteichefs auf die Probleme der DDR. Um diese rasch in den Griff zu bekommen, müsse er zu einer vollständigen Abriegelung gegen den Westen, d. h. zur Sperrung der Grenze in Berlin, ermächtigt werden. Adenauer und sein Regime seien verstärkt bemüht, den Westteil der Stadt „als vorgeschobenen Posten für ihre Revanchepolitik auszunutzen.“ Darum sei weiterhin der Abschluß des Friedensvertrages unerläßlich. Die UdSSR und ihre Verbündeten hätten „den Westmächten zwei Jahre Zeit gelassen“, sich damit vertraut zu machen; nun müsse man endlich handeln. Vor allem komme es auf die Umwandlung West-Berlins in eine „Freie Stadt“ an, welche die dortigen „Spionage- und Diversionsorganisationen“ beseitige und die Tätigkeit des Rundfunks RIAS beende. Damit würde der Frieden nicht nur für die DDR, sondern für alle sozialistischen Staaten gewährleistet werden. Das erfordere Opfer. Die DDR stehe vor dem Problem, sich „gegen die wirtschaftlichen Störmaßnahmen aus Westdeutschland zu sichern“. Der Hinweis auf die deswegen „zwingende Notwendigkeit, alle Maßnahmen und Pläne in den Staaten des Warschauer Vertrages untereinander abzustimmen“, sollte den östlichen Ländern Hilfe und Unterstützung zur moralischen Pflicht machen. ${ }^{41}$ Ulbricht soll auch die - im Manuskript nicht enthaltene - Bemerkung gemacht haben, die DDR könne den Verbündeten wegen des Abflusses von Ressourcen über die offene Grenze nicht die vertraglich vereinbarten Güter liefern. Die Wirtschaft seines Landes lasse sich nur in Ordnung bringen, wenn die Sektorengrenze geschlossen werde. ${ }^{42}$

Mit diesem Verlangen setzte er sich nicht durch.43 Chruschtschow hob in seiner Erwiderung die Notwendigkeit hervor, Kennedy die Chance einer Einigung zu

40 Gespräch M. G. Pervuchin - W. Ulbricht, 22. 3. 1961, RGANI, 5, 49, 377 (rolik 8978), Bl. 18-23.

41 Wortlaut der Rede W. Ulbrichts am 29. 3. 1961 auf der Tagung der Staaten des Warschauer Vertrages in Moskau am 29. 3. 1961, SAPMO-BArch, DY 30/3386, Bl. 161-180.

42 István Néméth, Historische Einführung, in: István Horváth, Die Sonne ging in Ungarn auf. Erinnerungen an eine besondere Freundschaft, München 2000, S. 95. In gleichem Sinne Honoré M. Catudal, Kennedy and the Berlin Wall Crisis, [West-]Berlin 1980, S. 49f. (nach Aussagen des tschechischen Überläufers Jan Šejna). Wie die Einordnung der Akte durch das Bundesarchiv vermuten läßt, hatte Ulbricht in diesem Sinne bereits den Entwurf für eine gemeinsame Erklärung formuliert (Entwurf einer Erklärung der Regierungen der Warschauer-Pakt-Staaten, o.D., SAPMO-BArch DY 30 3386, Bl. 181-187). Da der Text jedoch genau der Deklaration des Politischen Konsultativkomitees im August 1961 entspricht, ist ein Einordnungsirrtum nicht ausgeschlossen.

43 Die - auf ungenannten amerikanischen Quellen beruhende - Angabe von Michael R. Beschloss, Powergame. Kennedy und Chruschtschow. Die Krisenjahre 1960-1963, Düsseldorf 1991, S. 271, Chruščëv habe der Abriegelung der Sektorengrenze bereits damals „im Prinzip zugestimmt“, läßt sich weder aufgrund der Dokumente, die in der vorigen Fußnote genannt wurden, noch angesichts der folgenden Geschehnisse aufrechterhalten. Ulbrichts Äußerung auf der Pressekonferenz am 15. 6. 1961, „niemand“ habe die Absicht, „eine Mauer zu bauen“ (wiedergegeben in: Dokumente zur Deutschlandpolitik, hrsg. vom Bundesministerium für Innerdeutsche Beziehungen, Reihe IV, Bd. 6/2, Frankfurt/Main 1975, S. 933 f.), entsprach der Realität des damaligen Augenblicks. 
geben. Nur wenn das Gipfeltreffen ergebnislos bleibe, solle man einseitig vorgehen und den separaten Friedensvertrag unterzeichnen mit allen daraus folgenden Risiken. ${ }^{44}$ Er sicherte Ulbricht erneut zu, er halte am Programm von 1958 fest. West-Berlin müsse eine separate politische Einheit, eine selbständige Stadt werden, die in jeder Hinsicht von der Bundesrepublik getrennt sei. Die Zeit sei aber dafür noch nicht reif. Die Westmächte ließen sich vorerst nicht darauf ein, weil das mit einem großen Prestigeverlust und dem Ende ihrer Rüstungspläne verbunden wäre. Der Abschluß des Separatfriedens mit der DDR sei zwar notwendig, lasse sich aber im Augenblick nicht verwirklichen, werde aber unweigerlich auf die Tagesordnung kommen, auch der Zeitpunkt noch nicht abzusehen sei. Es sei zu bedenken, daß sich dann das Verhältnis zur Bundesrepublik zuspitzen werde. Auch die westlichen Staaten würden voraussichtlich heftig reagieren, sich letztlich jedoch mit der Veränderung abfinden. Die Lage in West-Berlin werde sich normalisieren. Botschafter Perwuchin fügte der Aussage später den Kommentar hinzu, dann erhalte die Oder-Neiße-Grenze endgültigen Charakter, die DDR werde ein international anerkannter Staat, und der Besatzungsstatus West-Berlins entfalle. Trotzdem würden die Westmächte voraussichtlich ihre Präsenz aufrechterhalten. Dann aber müßten sie genauso wie die Bundesrepublik die Ordnung des Personen- und Gütertransits durch ein Abkommen mit der DDR regeln, sofern sie nicht zu Gewalt griffen. Das aber sei unwahrscheinlich, weil die UdSSR und ihre Verbündeten mit militärischer Gegenwehr reagieren würden. ${ }^{45}$

Auch Kádár und Ceauşescu sollen sich gegen eine Abriegelung West-Berlins gewandt haben. Alle bekräftigten das Ziel des Friedensvertrages. Die DDR müsse danach unbedingt volle Souveränität auf ihrem Territorium erhalten, während West-Berlin in eine „Freie Stadt“ umzuwandeln sei.46 Am Rande der Tagung wurde über das Vorgehen beim geplanten Abschluß des Separatvertrages mit der DDR beraten. Alle meinten, das Problem müsse irgendwann, früher oder später, gelöst werden. Es gehe nicht an, den bisherigen Zustand noch jahrelang zu dulden. Die weitere Aufrüstung der Westdeutschen und ihre Ausstattung mit Kernwaffen könnten nicht akzeptiert werden. Ebensowenig sei hinzunehmen, daß West-Berlin faktisch zum „Herd der Provokation“ werde. Man müsse darauf hinarbeiten, daß die Frage der Lösung nähergebracht und schließlich wirklich gelöst werde. Dabei müsse berücksichtigt werden, daß die Bundesrepublik bei Zuspitzung des Konflikts zum Wirtschaftsboykott greife. Dem würden sich die westlichen Länder voraussichtlich für kürzere oder längere Zeit anschließen. Deswegen brauche man vorerst nichts Besonderes zu unternehmen, müsse aber die eigene Basis in je-

44 Hope M. Harrison, Driving the Soviet up the Wall. Soviet - East German Relations 1953-1961, Princeton/NJ-Oxford 2003, S. 167 f. unter Hinweis auf einen übersetzten Text, der im Tschechischen Zentralarchiv, Archiv des ZK der KPČ, Signatur Bd. 303/387, vorliegt.

45 István Rostás an Károlyi Kiss/Imre Hollai über ein Gespräch mit Botschafter Pervuchin (ungar.), 25. 4. 1961, MOL 288.f.32/1961/12.ö.e., Bl. 160 f.

46 Hinweis im Schreiben von W. Ulbricht an N. S. Chruščëv, 5. 7. 1961, SAPMO-BArch, DY 30 3386, Bl. 212 f. (deutsches Original), 217 f. (russ. Übersetzung); Rešenie Političeskogo Konsul'tativnogo Komiteta gosudarstv-učastnikov Varšavskogo Dogovora, o.D. [29. 3. 1961], SAPMOBArch, DY 30/3386, Bl. 151 f.; Politische Abteilung [des MfAA der DDR]: Kurseinschätzung der Deutschlandpolitik der Sowjetunion 1959-1964, 27. 4. 1964, PA-MfAA, A-276, Bl. 184. 
der Hinsicht funktionsfähig halten und die Kooperation unter den sozialistischen Staaten weiterentwickeln. ${ }^{47}$

Von einer Grenzsperrung war offenbar keine Rede mehr. Daher ist die Angabe eines westlichen Journalisten, diese sei als künftige Eventualität erwogen worden und die DDR habe eine Ermächtigung zu organisatorischen Vorbereitungen erhalten, die daraufhin bereits angelaufen seien, ${ }^{48}$ höchst zweifelhaft. Der folgende Meinungsaustausch zwischen Moskau und Ost-Berlin deutet in eine andere Richtung. ${ }^{49}$ Es gibt auch keinen Beleg für die von Matthias Uhl und Armin Wagner vertretene These, Ulbricht sei es „mit seiner Rede und in möglichen Vier-AugenGesprächen offensichtlich“ gelungen, Chruschtschow „erstmals von der Unvermeidbarkeit der Schließung der Grenze in Berlin zu überzeugen“ und von ihm die Erlaubnis zur Fortsetzung der „Planungen für eine militärische Abriegelung West-Berlins“ zu erlangen. ${ }^{50}$ Beide Autoren nehmen zudem selbst auf ein Dokument Bezug, das ausdrücklich feststellt, Ulbrichts Begehren widerspreche der sowjetischen Politik. ${ }^{51}$

Nachdem schon im Januar die Ausrüstung der DDR-Truppen mit Flakraketen vorgesehen worden war, 52 beschlossen die Parteichefs weitere militärische Vorkehrungen für den Fall einer Konfrontation wegen Berlin. Große Bedeutung kam dabei dem Vorhaben zu, eine gemeinsame Kommandostabsübung von Streitkräf-

47 Äußerungen von János Kádár auf der Sitzung des ZK der UVAP (ungar.), 10. 6. 1961, MOL 288. f. 4/41.ö.e., Bl. 26.

48 So Peter Wyden, „Wir machen Berlin dicht“, in: Der Spiegel, 41/1989, S. 161.

49 Mit Wydens These ließe sich insbesondere nicht erklären, wieso Ulbricht im Frühsommer gegenüber Chruščëv zu dem verzweifelten Argument griff, bei weiterhin offener Grenze sei mit dem Zusammenbruch der DDR zu rechnen, für den er dann keine Verantwortung mehr übernehmen könnte. Dieser Vorgang läßt darauf schließen, daß der Kremlchef damals die Idee von Sperrmaßnahmen noch prinzipiell ablehnte. Über die Bildung der Honecker-Kommission zum behaupteten Apriltermin ist nichts bekannt, vgl. A. Wagner, a.a.O., S. 436-438. Falls dieses vorbereitende Gremium schon im April bestanden haben sollte, müßte es sich um die vom SED-Politbüro schon am 10. 1. 1961 eingesetzte Arbeitsgruppe handeln, über deren Beratungen und Vorschläge keine Informationen vorliegen. In diesem Falle wären dies Eventualvorbereitungen, die Ulbricht von sich aus eingeleitet hätte und die daher nicht mit Beschlüssen des Warschauer Pakts am 28./29. 3. 1961 in Zusammenhang zu bringen wären.

50 Matthias Uhl, „Westberlin stellt also ein großes Loch inmitten unserer Republik dar“. Die militärischen und politischen Planungen Moskaus und Ost-Berlins zum Mauerbau, in: Dierk Hoffmann/Michael Schwartz/Hermann Wentker, Vor dem Mauerbau. Politik und Gesellschaft in der DDR der fünfziger Jahre, München 2003, S. 315. Vgl. Matthias Uhl/Armin Wagner, Einleitung, in: Matthias Uhl/Armin Wagner (Hrsg.), Ulbricht, Chruschtschow und die Mauer. Eine Dokumentation, S. 24.

51 Sie weisen darauf hin, daß es in einem Bericht Pervuchins an Gromyko vom 19.5. 1961 heißt, die DDR denke „entgegen der sowjetischen Linie“ an eine sofortige Schließung der Sektorengrenze (ebd.). Die zugleich ausgesprochene Vermutung, Ulbrichts vielbeachtete Außerung auf seiner Pressekonferenz vom 15. 6. 1961, niemand habe die Absicht, eine Mauer zu errichten, könnte „ein Signal oder Druckmittel gegenüber dem Kreml“ gewesen sein (ebd., S. 24 f.), läßt außer Betracht, daß der SED-Chef nur die zu dieser Zeit bestehende Tatsache aussprach: Chruschtschow war zur Abriegelung West-Berlins nicht bereit, und daher konnte auch die ostdeutsche Führung nicht daran denken. Das räumen faktisch auch Uhl und Wagner ein, wenn sie erklären, Ulbricht habe, ungeachtet der (nach ihrer Meinung) angelaufenen Vorbereitungen zum Mauerbau, „nicht einfach eine simple Lüge“ ausgesprochen, weil er „ja tatsächlich die Befestigung der Staatsgrenze [in Berlin] ursprünglich nicht favorisierte, sondern eben die Kontrolle der Zufahrtswege [West-Berlins] vorgezogen hätte“, diese aber „vor und auch nach der Pressekonferenz im Juni in Moskau nicht durchsetzen“ konnte (ebd., S. 25).

52 Verteidigungsminister H. Hoffmann an W. Ulbricht, 19. 1. 1961, BArch-MArch, AZN 32595, B1. 2. 
ten der UdSSR und DDR durchzuführen, um die Fragen zu klären, „die mit der Führung von Gefechtshandlungen in der Anfangsperiode eines Krieges in Zusammenhang stehen." 53 Bei der Durchführung im Mai zeigte sich nach amtlicher Feststellung, daß auch die ostdeutschen Verbände die „Fähigkeit zur Erfüllung aller ihrer Aufgaben unter allen Voraussetzungen" besaßen.54 Im April veranlaßte Ulbricht Schritte „zur Erhöhung der Sicherheit der Deutschen Demokratischen Republik“, über deren Art nichts Genaueres bekannt ist. ${ }^{55}$ Am 5. Mai ordnete er Maßnahmen zur Sicherung der Sektorengrenze an, die vor allem Personenkontrollen auf den dorthin führenden Straßen und Wegen vorsahen. ${ }^{56}$ Sofern der Kreml zustimmte, war das geeignet, eine weitergehende Abriegelung des SEDStaates gegen West-Berlin vorzubereiten.

\section{Einschätzung der amerikanischen Haltung in der Berlin- und Deutschland-Frage}

Das Scheitern der vom US-Geheimdienst unterstützten Landeoperation an der kubanischen Schweinebucht Mitte April $1961^{57}$ veränderte die Koordinaten der sowjetisch-amerikanischen Beziehungen. Kennedy verlor in der internationalen Öffentlichkeit an Ansehen und galt fortan den Moskauer Akteuren als Politiker, der weder den Einfluß der „Reaktionäre“ abwehren noch das von ihnen erwirkte Vorgehen durchführen konnte. Nachdem zudem kurz vorher Gagarin von der UdSSR aus als erster Mensch ins Weltall gestartet war, sah sich Chruschtschow in der Überzeugung bestätigt, daß sich die Verhältnisse in der Welt immer mehr in sozialistischem Sinne entwickelten, während die kapitalistischen Staaten ihren Einfluß immer weniger zur Geltung bringen könnten. Er wollte seinen Vorteil möglichst bald im Gespräch mit Kennedy ausnutzen. Dabei sollten vor allem die deutschen Probleme gelöst werden, die ihm auf den Nägeln brannten. Dagegen schien es aus amerikanischer Sicht vordringlich, das Vertrauen der NATO-Partner in den Präsidenten wiederherzustellen. Der Dialog mit der UdSSR war nicht so eilig. Der Kreml wartete vergebens auf einen Terminvorschlag für das Gipfeltreffen und fragte in Washington nach, wie es damit stehe. Kennedy war innerlich gespalten. Zum einen hatte er wenig Lust, unter den obwaltenden Umständen mit Chruschtschow zu sprechen, zum anderen aber wollte er ihn persönlich davon überzeugen, daß sein Verzicht auf Korrektur des Mißerfolgs an der Schweinebucht nicht als Zeichen der Schwäche anzusehen sei. Er schwankte und zögerte mit der Antwort. 58

53 Marschall A. Grečko an Generaloberst H. Hoffmann, 16. 6. 1961, BArch-MArch, AZN 32595, Bl. 18-21; Bericht des Ministeriums für Nationale Verteidigung an den Nationalen Verteidigungsrat über die gemeinsame zweistufige Kommandostabsübung vom 13.-30. Mai 1961, o.D., BArchMArch, VA-01/6301, Bl. 1-26.

54 Honeckers Referat vor dem ZK am 3./4. 7. 1961, in: Stenographische Niederschrift der 13. Tagung des ZK der SED, SAPMO-BArch, DY 30 2/1/257, Bl. $107 \mathrm{f}$.

55 A. Wagner, a.a.O., S. 438.

56 Ebd., S. 444, 446.

57 A. Fursenko/T. Naftali, a.a.O., S. 82-100.

58 Ebd., S. 101-106; Oleg Grinevskij, Tysjača i odin den' Nikity Sergeeviča, Moskau 1998, S. 350 f. 
Der Präsident glaubte zunächst, er könne sich mit dem Kremlchef schon über Berlin verständigen und damit die Grundlage für ein besseres Verhältnis zur UdSSR schaffen. Das sei bislang nur durch Dulles' verfehlte Politik verhindert worden. Berater überzeugten ihn jedoch davon, daß in der Berlin-Frage nicht mit einem Einvernehmen zu rechnen sei. Anderswo, vor allem auf den Feldern der Rüstungskontrolle und Weltraumerkundung, lasse sich aber eine Zusammenarbeit herstellen. Kennedy faßte speziell ein Abkommen über den Kernwaffenteststopp ins Auge. Ende April stellte sein Bruder die Position gegenüber der sowjetischen Kontaktperson dar. Dabei warnte er davor, die Entschlossenheit Washingtons zu unterschätzen. Andernfalls werde man sich zu „korrigierender Aktion“ genötigt sehen und von jeder Kompromißbereitschaft abrücken. Der Präsident habe aber noch nicht die Hoffnung auf Einvernehmen aufgegeben, obwohl ihn die „unglücklichen Geschehnisse in Kuba und Laos“ abgekühlt hätten. Robert Kennedy stellte eine Übereinkunft über den Teststopp in Aussicht, falls die UdSSR dazu die Initiative ergreife. Danach könne eine weitere Vereinbarung folgen. Zugleich erklärte er, sein Bruder sei am Gipfeltreffen nicht interessiert, wenn es dabei nur zu einem Meinungsaustausch komme. 59

Chruschtschow war froh, daß der Präsident an der geplanten Zusammenkunft festhielt. In seiner Antwort vom 12. Mai stellte er eine „gewisse“ Erhitzung der internationalen Atmosphäre wegen der Kuba betreffenden Ereignisse fest und erklärte, das sei eine gute Zeit, Ansichten auszutauschen. Kennedy zeigte sich gegenüber dem sowjetischen Botschafter, der das Schreiben überbrachte, enttäuscht über das Fehlen einer Aussage zu den zu treffenden Vereinbarungen und betonte die Notwendigkeit einer Abmachung über den nuklearen Teststopp. Andernfalls würden Fortschritte bei der Abrüstung zweifelhaft werden. Er wollte aber den Dialog zur Vorbereitung des geplanten Treffens fortsetzen und betonte die weiterhin bestehende Absicht zu dessen Durchführung. ${ }^{60}$ Darauf reagierte Chruschtschow wiederum anders, als man in Washington gedacht hatte. Statt das erwartete Entgegenkommen zu zeigen, ließ er mitteilen, die UdSSR verbinde mit Kennedys Amtsübernahme die Hoffnung, daß die Beziehungen wieder so werden könnten wie zur Zeit Roosevelts. Deshalb sei man auf das Angebot des Gipfeltreffens eingegangen. Die Vorstellung, es könnte „einseitige Zugeständnisse vonseiten der Sowjetunion“ geben, lehnte er nachdrücklich ab und übte offen Kritik an der BerlinPolitik des Präsidenten. Man hoffe, daß „die regierenden Kreise der Westmächte politischen Mut zeigen und die sowjetische Position in der deutschen Frage akzeptieren." Vor allem müsse sich der Westen zur Unterzeichnung des Friedensvertrages und zur Entscheidung in der West-Berliner Angelegenheit entschließen. Andernfalls bleibe der UdSSR nichts anderes übrig, als den Separatvertrag mit der DDR mit allen sich daraus für West-Berlin ergebenden Konsequenzen abzuschließen. 61

Kennedy nahm die Zurückweisung wenig ernst und hoffte weiter darauf, Chruschtschow von der Möglichkeit eines Kompromisses zu überzeugen. Im

59 A. Fursenko/T. Naftali, a.a.O., S. 106-114.

60 Ebd., S. $116 f$.

61 Ebd., S. 117-123. 
Blick darauf ließ er die Vorschläge für einen Stopp der Nukleartests überarbeiten. Dem Kreml teilte er mit, er sehe die Verbesserung der Beziehungen zur UdSSR als wichtigste Aufgabe an und verstehe die Sorgen wegen des „deutschen Revanchismus". Das erweckte den Eindruck, als wolle er einen sehr hohen Preis für eine Verständigung zahlen und sei daher zu großen Konzessionen in Berlin bereit.62 Das führte zu einer groben Fehleinschätzung im Kreml. Chruschtschow glaubte um so bereitwilliger an ein Nachgeben der USA, als dies seinem Glauben an den gesetzmäßigen Sieg des Sozialismus entsprach. Im Gespräch mit Thompson am 23. Mai machte er deutlich, ihm gehe es nicht um den Teststopp, sondern um Berlin als Ort „ständigen Schmerzes“. An der Abrüstung habe er wenig Interesse, solange die Berlin-Frage offen sei. Er äußerte sich enttäuscht darüber, daß es ihm nicht gelungen sei, den Westen vom Ende seiner Geduld mit der anomalen Situation im Herzen Europas zu überzeugen. Wenn man sich weigere, das Problem auf diplomatischem Wege zu lösen, werde er den Separatvertrag mit der DDR abschließen und sie zur Schließung des Zugangs nach West-Berlin ermächtigen. Den Hinweis des Botschafters, dann werde es zu einer gewaltsamen Auseinandersetzung kommen, konterte er mit dem Bemerken, das würde den sowjetischen Truppen - anders als ihren westlichen Gegnern - nichts ausmachen. Kennedy erkannte nun, daß die Gegenseite seinen Willen zur Verteidigung der Verpflichtungen der USA unterschätzte. Daher verwendete er in einer öffentlichen Ansprache am 25. Mai schärfere Formulierungen als ursprünglich vorgesehen. ${ }^{63}$

Das Scheitern der Landung in der Schweinebucht stärkte das sowjetische Selbstvertrauen sehr. Wie Botschafter Perwuchin seinem ungarischen Kollegen darlegte, herrschte in Washington große Sorge wegen der Möglichkeit, daß die UdSSR den Separatvertrag mit der DDR schließen werde. Man habe von dort durch mehrere Signale die Bereitschaft zu erkennen gegeben, auf einer VierMächte-Konferenz allein über die Regelung der West-Berlin-Frage zu sprechen. Der sowjetische Diplomat erwartete, daß die amerikanische Seite, wenn sie sich mit der unmittelbaren Aussicht auf Abschluß des Separatvertrags konfrontiert sehe, den Versuch machen werde, diesen durch ein auf die Stadt beschränktes Arrangement zu verhindern. Als Hauptgegner von Berlin-Konzessionen betrachtete er den westdeutschen Bundeskanzler. Adenauer tue alles, um die USA von einem Entgegenkommen abzuhalten. Es sei aber zu erwarten, daß die Westmächte weitergespannte Interessen hätten, die sich nicht in allen Punkten mit seinen Vorstellungen deckten. ${ }^{64}$

${ }_{62}$ G. Bol’šakov, Gorjačaja linija. Kak dejstvoval sekretnyj kanal Džon Kennedi - Nikita Chruščëv, in Novoe vremja, 20.1. 1989, S. 38-40.

63 A. Fursenko/T. Naftali, a.a.O., S. 123 f. Zusammenfassung der Rede 1t. UPI, 25. 5. 1961: Archiv der Gegenwart, XXXI. Jahrgang 1961, S. $9107 \mathrm{f}$.

64 Botschafter Pervuchin im Gespräch mit dem ungarischen Botschafter in Ost-Berlin: István Rostás an Károlyi Kiss/Imre Hollai (ungar.), 25. 4. 1961, MOL 288.f.32/1961/12.ö.e., Bl. 161. 


\section{Überlegungen Chruschtschows und Beschluß des ZK-Präsidiums der KPdSU}

Ulbricht hatte sich zwar auf der Warschauer-Pakt-Tagung Ende März mit seinem Vorschlag nicht durchsetzen können, die Sektorengrenze zu schließen, hielt aber daran weiter fest. Gegenüber Perwuchin drang er Mitte Mai erneut darauf, daß er dort die Kontrolle in die Hand bekommen müsse, um „das Tor zum Westen zu schließen“, den Exodus der Bevölkerung einzuschränken und den Einfluß der von West-Berlin aus agierenden wirtschaftlichen Verschwörung zu verringern. Der Botschafter kritisierte in seinem Bericht über das Gespräch die Ungeduld, mit welcher der SED-Chef die Beseitigung der Überreste der Besatzungszeit fordere, und seine Einseitigkeit, die ihn die Interessen des sozialistischen Lagers als Ganzem und die momentane internationale Lage nicht bedenken lasse. Wenn man seinem Verlangen nachgebe, die freie Bewegung zwischen DDR und West-Berlin so bald wie möglich mit allen Mitteln zu stoppen, würde das den Kampf um den Friedensvertrag erschweren. ${ }^{65}$

Chruschtschow war der gleichen Meinung. Am 26. Mai unterbreitete er dem Parteipräsidium im Blick auf das bevorstehende Treffen mit Kennedy Lagebeurteilung und Vorschläge. Gleich zu Anfang bezeichnete er den Präsidenten als „Hundesohn“, obwohl er dessen Grundthese zustimmte, daß sich seit 1955 (als der Westen und die UdSSR dem deutschen Staat auf ihrer jeweiligen Seite die Achtung der Vier-Mächte-Rechte zur Pflicht gemacht hatten) die Lage geändert habe. Dem müsse man Rechnung tragen. Er wandte sich kategorisch gegen das von Thompson unterbreitete Angebot eines Friedensvertrags mit Deutschland, der die westlichen Rechte in Berlin nicht berühre, und betonte, der Krieg würde nicht von der UdSSR, sondern von den Westmächten ausgehen, wenn diese die Folgen des - vielleicht erforderlichen - Separatvertrags mit der DDR nicht akzeptierten. Für ihre Haltung gebe es keinen vernünftigen Grund: Die Freiheit West-Berlins, welche die USA angeblich schützen wollten, würde durch Nichteinmischungsgarantien gewährleistet werden. Ein Krieg aber würde für Deutschland, Frankreich und andere europäische Länder die sofortige nukleare Vernichtung bedeuten. Man habe seit November 1958 genug Geduld gezeigt; jetzt müsse endlich eine Entscheidung fallen. Offenbar sei mit Washington und Bonn keine Verständigung möglich. Diesen Knoten werde man durchhauen - mit erheblichen Folgen für die NATO. Wenn die Bundesrepublik dieser für diesen Fall den Austritt androhe, solle sie doch gehen! Es sei nicht Sache der Sowjetunion, sich um den Zusammenhalt der NATO zu sorgen. Aber Westdeutschland drohe nur. Es könne und werde nicht austreten.

Chruschtschow ging davon aus, daß der Westen versuchen werde, der UdSSR Kriegsfurcht einzujagen, und wies auf die unterschiedlichen Standpunkte hin, die im NATO-Rat vertreten worden seien. Die aggresssive Haltung der [West-]Deut-

65 M. Pervuchin an A. Gromyko, 19. 5. 1961, AVPRF, 0742, 6, 46, 34, Bl. 2 f., in engl. Übersetzung wiedergegeben bei Hope M. Harrison, Ulbricht and the Concrete „Rose“: New Archival Evidence on the Dynamics of Soviet - East German Relations and the Berlin Crisis, 1958-1961, Working Paper No. 5, Cold War International History Project, Mai 1993, Appendix C. 
schen überrasche nicht, mache aber keine Angst, denn sie entscheide nicht über den Kriegsbeginn. Am gefährlichsten sei Amerika. Dort gebe es nach dem Tod von Dulles keinen starken Mann mehr. Mit dem Amtsantritt Kennedys habe sich das nicht geändert. Wie das Vorgehen gegen Kuba gezeigt habe, machten in Washington einzelne Gruppen ihren Einfluß geltend. Weil die Entscheidungen auf dieser Grundlage statt nach den Regeln der Logik getroffen würden, lasse sich das Verhalten der Amerikaner nicht sicher prognostizieren. Daher könnten sie einen Krieg anfangen. Dagegen sei klugen Politikern in Westeuropa, auch in der Bundesrepublik, klar, daß sie sich keinen Krieg leisten könnten, weil Atomwaffen auf ihrem Gebiet zum Einsatz kommen würden. Zudem lasse sich die Öffentlichkeit gegen den Krieg mobilisieren. Mit dem Abschluß des Friedensvertrages gehe die UdSSR trotzdem ein gewisses Risiko ein. Mit 95\% Wahrscheinlichkeit werde es aber keinen Krieg geben.

Dann erläuterte Chruschtschow das geplante Vorgehen. Die UdSSR werde West-Berlin nicht angreifen, sondern den Luftverkehr unterbrechen und ihre Bereitschaft zu dessen Aufrechterhaltung erkennen lassen, falls die westlichen Flugzeuge auf Flugplätzen der DDR in der Nähe Berlins landeten. Sie werde auf diese Weise nicht den Abzug der westlichen Truppen fordern. Deren Präsenz sei zwar nach sowjetischer Ansicht unrechtmäßig, aber sie werde weder Gewalt zu ihrer Beseitigung anwenden noch die Nahrungszufuhr sowie andere Lebensadern abschneiden oder sich in die inneren Angelegenheiten der Stadt einmischen. Damit werde sich faktisch nichts außer der Rechtsform ändern, so daß, wie unausgesprochen blieb, kein Grund für einen Krieg entstand.

Mit Befriedigung notierte Chruschtschow, daß Thompson von der Notwendigkeit gesprochen habe, die deutsche Ostgrenze der Nachkriegszeit vertraglich zu fixieren. De Gaulle habe das schon früher gesagt, aber auf amerikanischer Seite sei das neu. Als Wladimir Kusnetzow mit einem Zwischenruf darauf hinwies, der Botschafter habe auch Verständnis für die Sorge wegen des Exodus aus der DDR bekundet und Schritte zu dessen Beendigung angeregt, erläuterte Chruschtschow, dieser habe den sowjetischen Willen zum Abschluß eines Friedensvertrags auf die Absicht zurückgeführt, durch die Übertragung der Kontrolle der Verkehrswege an die DDR den Flüchtlingsstrom zu stoppen, und hinzugefügt, das lasse sich auch auf andere Weise erreichen. Dazu lasse sich doch nach seiner Ansicht etwas ausarbeiten. Mithin, so folgerte der sowjetische Parteichef, seien die USA beunruhigt. Thompsons Äußerung habe er mit der Feststellung beantwortet, die DDR sei ein souveräner Staat, der das Recht zur Kontrolle habe. Das sei aber nicht die Hauptsache. Es gehe vielmehr vor allem anderen darum, den Kriegszustand und das Besatzungsregime zu liquidieren. Weiter führte Chruschtschow aus, der Flugverkehr mit West-Berlin beunruhige Ulbricht. Er dränge auf Änderung, denn es gehe nicht an, daß die DDR Ingenieure und Ärzte ausbilde und nichts gegen ihren Weggang unternehmen könne. Für diese Ansicht gebe es bei den Verbündeten gewisse Sympathie. Inkonsequenz und Zögern kosteten die sowjetische Politik Vertrauen. Das müsse ein Ende haben.

Chruschtschow hielt die sowjetische Position für „sehr stark“. Man müsse aber davon auch Gebrauch machen. Wenn westliche Flugzeuge [nach Abschluß des Friedensvertrages weiterhin] kämen, müsse man diese abschießen. Tue die UdSSR 
das nicht, würde sie kapitulieren. Ein englisches Flugzeug sei bereits abgeschossen worden, als es den Luftkorridor verlassen habe. Macmillan habe das geschluckt. Hinterher habe man in London erklärt, das Flugzeug sei zufällig vom Weg abgekommen. Trotzdem sei es abgeschossen worden - eine deutliche Bestätigung, daß die Sowjetunion tue, was sie sage. Politik sei Politik. Wolle man seine Politik durchsetzen und ihre Anerkennung und Respektierung erreichen, dann müsse man hart sein. Der sowjetische Parteichef erklärte weiter, die Militärs seines Landes sollten sich das Kräfteverhältnis in Deutschland genau ansehen und melden, was noch benötigt werde. Sofern erforderlich, könne man - ohne Eile, im Laufe eines halben Jahres - Waffen und Soldaten heranführen, damit man eine starke Position habe, falls es zu einer „Provokation“ der anderen Seite komme.66 Indem Chruschtschow Flugzeuge, die das Recht auf freien Überflug in den Luftkorridoren weiter in Anspruch nehmen würden, zum Abschuß freigeben wollte, wich er von seinem eigenen Konzept ab, den Erstgebrauch von Waffengewalt und damit den Schritt zum Krieg dem Westen zu überlassen.

In der Diskussion meinte Mikojan, es könnte auch einen lediglich konventionellen Krieg geben. Das bedeutete ein geringeres Risiko; die Wahrscheinlichkeit der Kriegsvermeidung war daher niedriger - auf $90 \%$ - zu veranschlagen. Auf jeden Fall werde sich die Situation [bei Abschluß eines separaten Friedensvertrages] erheblich verschärfen. Er sprach sich daher für ein weniger hartes, diplomatischeres Vorgehen aus, war aber ebenfalls der Ansicht, daß die DDR im Endergebnis die Kontrolle über den Luftverkehr erhalten müsse. Wie das im einzelnen geschehen solle, werde erst nach Unterzeichnung des Friedensvertrags Anfang 1962 zu entscheiden sein. Chruschtschow unterstrich daraufhin nochmals, daß man die Flugverbindungen sofort in die Hand bekommen müsse. Es wäre ein Zeichen von Schwäche, wenn man noch „irgendeine Möglichkeit offener Türen“ ließe. Gromyko meinte, ein Krieg wegen Berlin sei „fast ausgeschlossen“. Weitere Präsidiumsmitglieder bekundeten ausdrücklich ihr Einverständnis mit den Ausführungen des Parteichefs. Da sich kein Einspruch erhob, war das Konzept gebilligt. 67 Die spätere Nachricht, Kennedy wolle den sowjetischen Interessen so weit wie möglich entsprechen, schien die Entscheidung als richtig zu bestätigen. Eine Äußerung Adlai Stevensons gegenüber dem Botschafter in Washington, Kennedy unterliege oft dem Einfluß „fragwürdiger und sogar gefährlicher Ratgeber“, bestärkte Chruschtschow in der Erwartung, daß er bei dem vorgesehenen Treffen entscheidend auf den Präsidenten einwirken könne. Den skeptischen Hinweis, $\mathrm{daß}$ sich nur beim Teststopp - also nicht zu Berlin - ein Sachergebnis erzielen lasse, scheint er dagegen ignoriert zu haben. ${ }^{6}$

66 Ausführungen von N. S. Chruščëv auf der Sitzung des Präsidiums des ZK der KPdSU, 26. 5. 1961, in: A. A. Fursenko (otv. red.), Archivy Kremlja. Prezidium CK KPSS 1954-1964. Černovye protokol'nye zapisi zasedanij. Stenogrammy, Moskau 2003, S. 500-507. Zu dem erwähnten Gespräch mit Thompson siehe auch Zapis' besedy N. S. Chruščëva s rukovodjaščimi dejateljami CK KPČ i pravitel'stva Čechoslovakii, 1. 6. 1961, in: Istočnik, 3/1998 (34), S. 88.

67 Protokoll der Sitzung des Präsidiums des ZK der KPdSU (TOP I), 26. 5. 1961, ebd., S. 498 f. Die verkürzte Wiedergabe in dem Protokoll läßt die Einwände Mikojans nur unvollkommen deutlich werden. Daher ist die Darstellung bei A. Fursenko/T. Naftali, a.a.O., S. 124 f., ergänzend heranzuziehen.

68 Ebd., S. 125-127. 


\section{Schwankungen und Überlegungen unmittelbar vor der Begegnung mit Kennedy}

Kurz vor der Wiener Begegnung beschlichen Chruschtschow jedoch Zweifel, ob das Gespräch zum Erfolg führen werde. Er sah zwar die sowjetische Position weiter als stark an, war sich aber nicht mehr sicher, ob er Kennedy dazu bewegen könne, an Friedensvertrag und Freistadtregelung mitzuwirken und die Kontrolle der DDR über die Zugänge West-Berlins zu akzeptieren. Wie er den tschechoslowakischen Führern in Bratislava auf dem Weg nach Wien erklärte, konnte es sich der Präsident eigentlich gar nicht leisten, auf das Verlangen nach Abschluß des Friedensvertrags einzugehen, denn das wäre der Anfang vom Auseinanderbrechen der NATO. Die USA, in denen die Westmächte ihre Hauptstütze sähen, würden das Vertrauen der Verbündeten, vor allem der Deutschen, verlieren. Vermutlich würden viele Staaten die atlantische Allianz verlassen. Der Kremlführer rechnete daher kaum noch mit dem Einschwenken der Amerikaner, hielt es aber für unabdingbar, ausnahmslos alle Forderungen durchzusetzen. Falls die Westmächte doch noch zur Mitwirkung bereit wären, wollte er ihnen die seit Mitte 1959 angebotene Interimslösung - also eine zeitliche Streckung der politischen Kapitulation - zugestehen. Anderes kam für ihn nicht in Betracht, denn nur so könnten die seit 1958 ausgesprochenen Drohungen glaubwürdig bleiben und die Nöte des SED-Regimes behoben werden - beides in seiner Sicht ein wichtiges Moment der Stärke in der Auseinandersetzung mit dem Westen. ${ }^{69}$

Deswegen faßte Chruschtschow den Abschluß des Separatvertrags ernsthaft ins Auge. Wie er in Bratislava ausführte, war damit kein Risiko verbunden. Niemand könne die UdSSR daran hindern. Die USA würden sich auf keinen militärischen Konflikt einlassen. Macmillan, de Gaulle und Adenauer seien klug genug, um zu wissen, was ein Krieg für sie bedeute. Sogar Dulles habe auf Verhandlungen gesetzt. Allerdings wisse man bei Kennedy bislang nicht, was man von ihm zu halten habe. Wie sein Vorgehen gegen Kuba zeige, sei er „nicht sehr vernünftig“. Aber auch er müsse einsehen, daß er mit der Sowjetunion nicht so umspringen könne wie mit Kuba. Ihm bleibe als Gegenmaßnahme nur der Abbruch der diplomatischen Beziehungen, der unwirksam und daher wenig wahrscheinlich sei. In einer Verschärfung der internationalen Lage liege gleichwohl ein gewisses Risiko. Dieses könne die UdSSR angesichts ihrer Macht getrost eingehen, zumal sie im Endergebnis nur Positives zu erwarten habe. Sobald der Termin für den Friedensschluß mit der DDR feststehe, werde das Großkapital West-Berlin verlassen. Der Westen werde ohnmächtig dastehen; mit seinen leeren Drohungen werde er nichts erreichen. Dazu würden weiterreichende Erfolge kommen. Wenn der Separatvertrag mit der DDR abgeschlossen sei und die USA deswegen keinen Krieg begännen, würde das die Haltung der anderen NATO-Staaten stark beeinflussen. Die Deutschen, aber auch Länder wie Dänemark und die Niederlande würden sehen, daß sich die Amerikaner nicht um ihrer Verbündeten willen zum Krieg entschlössen, und würden daher ihre Bindungen an die NATO überprüfen. ${ }^{70}$

69 Ebd., S. 85-97.

70 Ebd. 
Chruschtschow stellte sich weiter die Frage, wann der Separatvertrag am besten abgeschlossen werden solle. Grundsätzlich hielt er es für möglich, sofort zu handeln, wie Ulbricht es wolle. Man könne aber auch bis nach den Bundestagswahlen im September warten und sehen, ob nicht statt Adenauer Brandt gewählt werde. Aber es sei schwer zu sagen, ob der besser wäre. Er ließ eine gewisse Präferenz für die Zeit nach dem XXII. KPdSU-Parteitag erkennen, damit die vorgesehene Verkündung eines Programms mit neuen Perspektiven für die kommunistische Bewegung nicht durch die Verschärfung der internationalen Situation belastet werde, mit der bei Abschluß des Separatvertrags zu rechnen sei. Für den späteren Termin sprach nach Ansicht des Kremlführers auch, daß dann die Bundestagswahlen stattgefunden hatten, die, wie er aufgrund einer Äußerung von Botschafter Kroll glaubte, voraussichtlich Adenauer das Amt kosten würden. ${ }^{71}$ Auf alle Fälle sollte die Entscheidung noch 1961 getroffen werden. ${ }^{72}$

\section{Wiener Begegnung mit Kennedy}

Die gegensätzlichen Standpunkte machten eine Übereinkunft auf dem Wiener Treffen am 3. und 4. Juni 1961 von vornherein zweifelhaft. Während es Chruschtschow entscheidend auf den Friedensvertrag und die Freistadtregelung ankam, wollte Kennedy diese Streitfragen zunächst in den Hintergrund rücken. Aus seiner Sicht galt es, vorher die Koordinaten des Gesamtverhältnisses zwischen beiden Supermächten zurechtzurücken. Erst danach könne man schwierige Einzelprobleme mit Aussicht auf Erfolg angehen. Der Präsident hoffte, auf dem Feld der Abrüstung gemeinsame Interessen und damit die Basis einer Verständigung zu finden. Der Kremlchef dagegen wollte Regelungen in diesem Bereich erst nach Durchsetzung seiner Berlin-Forderungen erörtern. Er argwöhnte, daß sein Gegenüber nur ausweichen wolle, wenn er vorher andere Fragen regeln wolle. Hinter diesem Dissens stand ein tieferliegender Gegensatz. Chruschtschow wollte jedes Einvernehmen prinzipiell auf die zwischenstaatlichen Beziehungen beschränken. Demnach konnte man sich allein über das Verhältnis von Regierung zu Regierung verständigen. Die ideologischen Differenzen dagegen, die auf der gesellschaftlichen Ebene ausgetragen wurden, sollten grundsätzlich außerhalb jeder Übereinkunft bleiben. ${ }^{73}$

Das hieß im Klartext, daß der Kreml - gemäß seiner Vorstellung von „friedlicher Koexistenz" - sich durch „gute Beziehungen“ zu den USA nicht vom „Kampf für seine revolutionären Ziele“, d.h. für die weltweite Durchsetzung des Sozialismus abbringen lassen wollte. Mit Unterstützung auch von Kräften innerhalb des westlichen Lagers sollte der Kapitalismus beseitigt und auf den „Müll-

71 Ebd.

72 Im Memorandum, das Chruščëv zur Übergabe an Kennedy mit nach Wien nahm, wurde eine „Frist von nicht mehr als sechs Monaten“ in Aussicht genommen (SAPMO-BArch, DY 30/J IV 2/ 2A/825, Bl. 15).

73 Diese Auffassung hatte Chruščëv dem amerikanischen Präsidenten ausdrücklich übermitteln lassen, siehe A. Fursenko/T. Naftali, a.a.O., S. 117. 
haufen der Geschichte“ geworfen werden. ${ }^{74}$ Die westlichen Vertragspartner hatten als objektiv feststehendes Faktum zu akzeptieren, daß „die Werktätigen der kapitalistischen Länder den Kampf gegen ihre Unterdrücker führen“ und daß „niemand eine Garantie geben wird, wenn sich etwa in Spanien das Volk gegen die Diktatur erheben und ein kommunistisches Regime errichten wird." Der sowjetische Verzicht auf die Anwendung von Gewalt galt demzufolge nur für die Beziehungen zu anderen Staaten, nicht aber, wie unausgesprochen signalisiert wurde, für das Verhalten bei Konflikten innerhalb westlicher Gesellschaften oder Kolonialreiche. ${ }^{75}$ Kennedy war nicht bereit, das als Geschäftsgrundlage anzunehmen. Die programmatischen Erklärungen, die Chruschtschow Anfang Januar abgegeben hatte, ${ }^{76}$ stimmten ihn besorgt. Er glaubte jedoch, ihn mit überzeugenden Argumenten zur Aufgabe seines Standpunkts veranlassen zu können. Daher sprach er, gegenteiligen Empfehlungen seiner Ratgeber zuwider, in Wien die prinzipielle Orientierung der sowjetischen Politik an, bevor die anstehenden Streitfragen zur Diskussion kamen.

Der Präsident eröffnete den Dialog mit dem Ausdruck der Beunruhigung über die „stürmischen“ Folgeerscheinungen von Revolutionen. Unter Hinweis auf die nuklearen Vernichtungspotentiale forderte er „größeres Verständnis zwischen beiden Seiten hinsichtlich der in der Welt entstandenen Lage und der jeweiligen Absichten“. Um der Notwendigkeit einer Verständigung über die beiderseitigen Absichten und Interessen Nachdruck zu verleihen, räumte er die Verfehltheit seines Vorgehens gegen Kuba ein, und deutete an, daß es auch im Kreml korrekturbedürftige „unrichtige Erwägungen“ gebe. Chruschtschow entgegnete, USA und UdSSR hätten „unterschiedliche Auffassungen von der Lage in der Welt“. Wie man in Washington glaube, sei die „Unzufriedenheit“ eines Volkes mit der herrschenden Ordnung in seinem Lande und das daraus erwachsende Bemühen um deren Ersetzung „durch eine andere, den Interessen des Landes mehr entsprechende“ Ordnung einfach eine „Ränke der Kommunisten“. Wenn sich ein Volk gegen Unterdrückung und Tyrannei erhebe, sei jedoch keineswegs „die Hand der Kommunisten, die Hand Moskaus im Spiel“. Daß die USA dies nicht verstünden, sondern die Geschehnisse falsch interpretierten, sei der Grund für die entstehenden Gefahren. Die Sowjetunion hege „für Diktatoren, Unterdrücker und Tyrannen kein Mitgefühl“, während die Amerikaner die „Konterrevolutionäre“ unterstützten, deren Herrschaft „Elend und Hungerdasein“ bringe und dadurch die Völker, die sich befreien wollten, in die Arme der Kommunisten trieben. Der Kremlführer illustrierte die Ausführungen mit dem Beispiel Kubas und warf den USA vor, sich das Recht zum Überfall auf alle Länder herauszunehmen, die eine andere Politik verfolgten. Nur durch den Verzicht auf derartige Interventionen könne es wieder mehr Ruhe in der Welt geben. ${ }^{77}$

74 N. S. Chruščëv, Za novye pobedy mirovogo kommunističeskogo dviženija. K itogam Soveščanija predstavitelej kommunističeskich i rabočich partij [Referat auf der Versammlung der Parteiorganisationen der Hohen Parteischule, der Akademie für Gesellschaftswissenschaften und des Instituts für Marxismus-Leninismus beim ZK der KPdSU vom 6. 1. 1961], in: Pravda, 25. 1. 1961.

75 Zapis' besedy N. S. Chruščëva s poslom SŠA v SSSR L. Tompsonom 9 marta 1961 goda, g. Novosibirsk, SAPMO-BArch, DY 30/3663, Bl. $15 \mathrm{f}$.

76 N. S. Chruščëv, Za novye pobedy, a.a.O.

77 Niederschrift der Unterredung N. S. Chruščëv - J. Kennedy (Übersetzung der DDR), 3. 6. 1961, 
Durch die Anschuldigungen sah sich Kennedy zu der Feststellung veranlaßt, er mache Castro nicht dessen Ablehnung der bisherigen Verhältnisse in seinem Land, sondern das Streben nach dem Aufbau fremder Stützpunkte zum Vorwurf, welche die Verhältnisse in Lateinamerika bedrohten. Zudem seien in Kuba keine freien Wahlen vorgesehen. Die USA repektierten jede Regierung, die ihre Macht „auf Grund der freien Entscheidung des Volkes“ erhalten habe. Darauf komme es an: Der Wandel müsse „auf friedlichem Wege“ erfolgen. Die Hauptsache sei, „daß das Volk das Recht hat, seine Regierungsform frei zu wählen. "Chruschtschow erklärte sich damit zwar einverstanden, doch ließen seine weiteren Äußerungen erkennen, daß er die Zustimmung des Volkes zu einem neuen Regime dadurch gewährleistet sah, daß sich die Machthaber zu behaupten vermochten. Dem Verlangen, niemand dürfe sich in die Angelegenheiten eines anderen Landes einmischen, legte er den Sinn bei, man dürfe nicht zur Bekämpfung revolutionärer Veränderungen eingreifen. Waffengewalt erschien ihm legitim, wenn sie - gemäß sowjetischer Interpretation - dem Interesse des Volkes diente. Wenn man sich darauf einigen könnte, meinte Chruschtschow, würden die Interessen der UdSSR und der USA „niemals in Konflikt geraten“. Kennedy gelang es nicht, den Kremlchef auf das Prinzip zu verpflichten, daß das internationale Gleichgewicht nicht mittels Gewalt verändert werden dürfe. Die Kontroverse konzentrierte sich danach auf das Vorgehen in der Dritten Welt. Während sich der Präsident dagegen wandte, daß der Kreml „nationale Befreiungskriege“, d. h. bewaffnete Kämpfe gegen westliche Staaten und deren Freunde, unterstütze, hielt sein sowjetischer Widerpart derartige „Volkskriege“ für gerecht und notwendig. Daraus folgte, daß die UdSSR im Bedarfsfalle zu Hilfe aufgerufen war. ${ }^{78}$ Der Gedankenaustausch machte klar, daß es keine Grundlage für ein gemeinsames Herangehen an außenpolitische Probleme gab.

In der Überzeugung, der politische Wandel zu Lasten des Westens sei ein ehernes Gesetz der geschichtlichen Entwicklung, ${ }^{79}$ konfrontierte Chruschtschow seinen Gesprächspartner in aller Härte mit der Forderung, daß sich die Westmächte seinem Willen in der Deutschland- und Berlin-Frage uneingeschränkt fügen müßten. Nur Scheinkonzessionen, wie sie der Kreml seit Mitte 1959 immer wieder angeboten hatte, wollte er erörtern. Wenn Kennedy nicht darauf eingehe, sehe sich die UdSSR gezwungen, den separaten Friedensvertrag mit der DDR abzuschließen, die westlichen Rechte in Berlin einseitig aufzuheben, der ostdeutschen Seite

wiedergegeben in: Heiner Timmermann (Hrsg.), 1961 - Mauerbau und Außenpolitik, Münster 2002, S. 345-353.

78 Ebd. In der Sicht Chruščëvs waren die „nationalen Befreiungskriege“ in der Dritten Welt und das politische Zusammenspiel des Sozialismus und der „nationalen Befreiungsbewegungen“ das aktuell wichtigste Moment des „sozialen Fortschritts“ in der Welt, d. h. des Voranschreitens zum Sozialismus. Die Ablehnung, die der sowjetische Führer dem Weltkrieg und überhaupt dem Krieg zwischen Staaten entgegenbrachte, galt nicht dem Krieg schlechthin: Er sah „lokale Kriege“, „Befreiungskriege“ und "Volksaufstände“ - also bewaffnete Auseinandersetzungen innerhalb von Staaten, die nicht von der nuklearen Abschreckung erfaßt wurden - als legitim und notwendig an (N. S. Chruščëv, Za novye pobedy, a.a.O.).

79 Am 6. 1. 1961 hatte Chruščëv vor maßgeblichen Repräsentanten des Sowjetregimes detailliert seine Ansicht dargelegt, daß der Sozialismus in unaufhaltsamem Vordringen begriffen sei, daß er immer neue Völker erfasse und daß sich dadurch der Einflußbereich der UdSSR fortlaufend ausbreite (N. S. Chruščëv, Za novye pobedy, a.a.O.). 
die Verfügungsgewalt über die Zugangswege zu übertragen und den damit geschaffenen Zustand notfalls mit militärischen Mitteln zu verteidigen. Er ging dabei so weit, den Westmächten ausdrücklich den Abschuß ihrer Flugzeuge anzudrohen, falls sie dann die Luftkorridore ohne Genehmigung der DDR weiter benutzen würden. Wie die sowjetischen Akteure befriedigt feststellten, erkannte Kennedy an, daß die Lage in Berlin und Deutschland „anomal“ sei und daß man sie „ändern“ müsse. Sie bemängelten, daß er sich unter Hinweis auf „Erwägungen des Prestiges“ weigere, aus West-Berlin abzuziehen, und daß er keine Vorschläge unterbreite, wie die Probleme von Friedensvertrag und Normalisierung zu lösen seien. Die Entscheidung darüber dürfe keinesfalls weiter aufgeschoben werden. Auch bei Teststopp und Abrüstung wurden gegensätzliche Standpunkte vorgetragen. Kennedy hatte daher keinen Erfolg mit dem wiederholten Bemühen, wenigstens zu partiellem Einvernehmen zu gelangen. 80

\section{Totale Konfrontation der Standpunkte}

Ein Memorandum Chruschtschows bekräftigte dessen unnachgiebige Position. ${ }^{81}$ In einem letzten Gespräch, um das der Präsident nachgesucht hatte, bejahte der Kremlchef die Frage, ob der Zugang nach Berlin bei Abschluß des Separatvertrags mit der DDR verwehrt werden würde. Daraufhin betonte Kennedy die Entschlossenheit, auf Gewalt mit Gewalt zu antworten, und beendete den Dialog mit den Worten, es werde einen kalten Winter geben. ${ }^{82}$ Das Rededuell hatte nach dem sowjetischen Protokoll noch schärfere Akzente. Demnach sagte Kennedy, die nach sechs Monaten vorgesehenen Aktionen - der Abschluß des separaten Friedensvetrages mit den daran geknüpften Konsequenzen - seien das, was er „am allermeisten verhütet wissen“ wolle. Man werde sich „von Angesicht zu Angesicht gegenüberstehen, gebunden durch völlig gegensätzliche Verpflichtungen [hier gegenüber der NATO, dort gegenüber der DDR], was zu verhängnisvollen Folgen führen“ müsse. Er bedauere, daß er „bei einer solchen Lage der Dinge aus Wien abreisen“ müsse. Chruschtschow warf ein, sie beide wollten doch den Frieden. Damit war der Präsident einverstanden, fügte aber warnend hinzu, es sei „leicht, den Krieg zu entfesseln“, aber „schwer, den Frieden zu sichern“. Der sowjetische

80 Doveritel'naja informacija o vstreče predsedatelja soveta ministrov SSSR N. S. Chruščëva s prezidentom SŠA D. Kennedi, o.D. [handschriftliche Eintragungen: 12. und 14. 6. 1961], AVPRF, 0129, 45, 329, 11, Bl. 113-116.

81 Memorandum, o.D. [Übergabe an Kennedy am 4. 6. 1961, Anlage zu Rundschreiben an die Mitglieder und Kandidaten des SED-Politbüros vom 8. 6. 1961], SAPMO-BArch, DY 30/J IV 2/2A/ 825, Bl. 11-16/Neues Deutschland, 11. 6. 1961/Pravda, 11. 6. 1961.

82 Memoranda of Conversations between Kennedy and Khrushchev, 4. 6. 1961, FRUS 1961-63, Vol. V: Soviet Union, http://www.state.gov/www/about_state/history/vol_v/86_89.html, S. 6-21; Talking Points Reviewing Conversations between President Kennedy and Chairman Khrushchev, prepared by the Department of State, 12.6. 1961, ebd., http://www.state.gov/www/about_state/ history/vol_v/90_99.html, S. 12 f.; Doveritel'naja informacija o vstreče predsedatelja soveta ministrov SSSR N. S. Chruščëva s prezidentom SŠA D. Kennedi, o.D. [handschriftlich: 12. und 14.6. 1961], AVPRF, 0129, 45, 329, 11, Bl. 113-116; G. M. Kornienko, Upuščënnaja vozmožnost'. Vstreča N. S. Chruščëva i Dž. Kennedi v Vene v 1961g., in: Novaja i novejšaja istorija, 2/1992, S. $100 \mathrm{f}$. 
Führer entgegnete, er habe drei Kriege erlebt und wisse, was sie dem Volk brächten, doch sei nicht er, sondern Kennedy derjenige, der mit dem Krieg drohe. Er nehme „lediglich die Herausforderung an“. Er werde „antworten müssen“, wenn der amerikanische Widersacher den Krieg beginne. Der Präsident wandte ein, daß doch Chruschtschow „die bestehende Lage ändern“ wolle. Das rief dessen Entgegnung hervor, er wolle [nur] Frieden und einen Friedensvertrag mit Deutschland, aber keine „Grenzen ändern oder andere Völker erobern“. Wenn er solche Absichten hätte, dann wäre Kennedy „tatsächlich verpflichtet, sich zu verteidigen“. Er, Chruschtschow, wolle ,jedoch nur den Frieden“. Amerikanische Drohungen würden ihn „nicht aufhalten“. Wenn der Präsident ihm „einen Krieg aufzwingen“ sollte, werde es „einen geben“. Das sei sein „unumstößlicher Entschluß“; man werde „den Friedensvertrag im Dezember dieses Jahres unterzeichnen“. Kennedy replizierte, es scheine „einen kalten Winter zu geben in diesem Jahr“. Chruschtschow betonte daraufhin, von seinem Entschluß werde er „nicht abgehen“, glaube aber, „daß trotzdem Frieden sein wird und daß sich nach der Unterzeichnung des Friedensvertrages unsere Beziehungen auf dem Wege der Freundschaft und der Zusammenarbeit entwickeln werden."83

Auch nach einem amerikanischen Ohrenzeugen, dessen Version im US-Protokoll nur schwach zum Ausdruck kommt, ${ }^{84}$ war der Wortwechsel von dramatischer Heftigkeit. Demnach dankte Kennedy für die Offenheit, mit der Chruschtschow seine Position dargelegt habe, und erklärte dann mit betonter Langsamkeit, Berlin sei nicht Laos (über das ebenfalls gesprochen worden war), sondern „von größter Bedeutung für die USA“. Nähmen sie den sowjetischen Vorschlag an, würden ihre Verpflichtungen [gegenüber den Verbündeten] als ein bloßer Fetzen Papier betrachtetet werden. „Westeuropa ist für unsere Sicherheit von zentraler Wichtigkeit, und wir sind dafür in zwei Kriegen eingetreten. Würden wir WestBerlin verlassen, würde auch Westeuropa aufgegeben werden [...] Das können wir nicht akzeptieren." Zunehmend ärgerlich entgegnete Chruschtschow, die Sowjetunion könne keine Welt akzeptieren, in der Hitlers Generäle, die für einen „Lebensraum von Berlin bis zum Ural“ gekämpft hätten, hohe Kommandeure der NATO seien. „Die UdSSR wird den Friedensvertrag unterzeichnen, und die Souveränität der DDR wird respektiert werden. Jede Verletzung dieser Souveränität wird von der UdSSR als Akt der offenen Aggression angesehen werden [...] mit allen Konsequenzen, die sich daraus ergeben." Kennedy fragte, ob dieser Friedensvertrag den Zugang nach Berlin blockieren werde, was sein Gesprächspartner bejahte.

Der Präsident wies darauf hin, daß dies die Vier-Mächte-Vereinbarung von 1945 aufheben würde. Das könnten die USA nicht akzeptieren. Der Kremlchef entgegnete, er wolle kein Mißverständnis darüber aufkommen lassen, daß dies Krieg bedeuten würde. „Wenn die USA einen Krieg wegen Deutschland beginnen wollen, dann soll es so sein [...] Falls es da einen Verrückten gibt, der Krieg will, dann sollte er in eine Zwangsjacke gesteckt werden. So, das ist die sowjetische Po-

83 Niederschrift der Unterredung N. S. Chruščëv - J. F. Kennedy in der Sowjetischen Botschaft, 4. 6. 1961, wiedergegeben in: H. Timmermann, a.a.O., S. $406 \mathrm{f}$.

84 Memorandum of Conversation, 4. 6. 1961, 3:15 p.m., in: FRUS 1961-1963, Bd. V: Soviet Union, Dokument 89, www.state.gov/www/about_state/history/vol_v, 86-89.html, S. 35. 
sition. Die UdSSR wird den Friedensvertrag Ende des Jahres unterzeichnen.“ Kennedy erwiderte, Chruschtschow solle verstehen, an sich sei die Unterzeichnung des Friedensvertrages kein kriegerischer Akt. „Jedoch ein Friedensvertrag, der uns unsere vertraglichen Rechte nimmt, ist ein kriegerischer Akt. Die Übertragung unserer Rechte an Ostdeutschland ist ein kriegerischer Akt. Nach weiterem Hin und Her gab Kennedy zu bedenken, man könne sich wechselseitig zerstören. Chruschtschow bestätigte das. Daraufhin appellierte der Präsident an seinen Gesprächspartner, ihn nicht in Situationen zu bringen, welche die nationalen Interessen der USA so stark beträfen, und betonte, das entscheidende amerikanische Interesse in Berlin seien die Zugangsrechte. Die sowjetische Seite könne einen Vertrag unterschreiben oder sonst tun, was sie wünsche, solange sie nicht die alliierten Besatzungsrechte in West-Berlin bedrohe. „Gewalt wird mit Gewalt beantwortet werden“, antwortete Chruschtschow. Die UdSSR stelle sich darauf ein, und er solle das ebenfalls tun. „Wenn die USA Krieg wollen, ist das ihr Problem. Es ist Sache der USA zu entscheiden, ob Krieg oder Frieden sein wird. Der Entschluß, den Friedensvertrag zu unterzeichnen, ist fest und unwiderruflich, und die Sowjetunion wird ihn unterzeichnen, wenn die USA ein Zwischenabkommen verweigern.“ Der amerikanische Präsident entgegnete: „Dann, Herr Vorsitzender, wird es Krieg geben. Es wird ein kalter Winter werden." 85

\section{Chruschtschows Eindruck von Kennedy}

Die Wiener Begegnung erbrachte zwar keine Ergebnisse, war aber nach sowjetischer Ansicht nützlich. Die bloße Tatsache, daß sich die beiden Führer getroffen hatten, war nach internem Bekunden als „guter Anfang für weitere Verhandlungen mit dem Ziel der Minderung der internationalen Spannung“ zu werten. Zugleich habe der Dialog über die Fragen begonnen, die der Lösung bedürften. ${ }^{86}$ Vor allem aber gewann Chruschtschow einen persönlichen Eindruck vom neuen Präsidenten der USA, den er bis dahin nicht recht einzuschätzen wußte. Das war ihm im Blick auf die bevorstehende Konfrontation äußerst wichtig. Mit welchen Reaktionen hatte er zu rechnen, wenn er mit dem angedrohten Separatvertrag und den damit verknüpften Konsequenzen für West-Berlin ernstmachte? Hatte er es mit einem schwachen, zu Nachgiebigkeit neigenden Widersacher zu tun, dem man ungestraft vieles zumuten konnte? Oder war die Ankündigung Kennedys zum Nennwert zu nehmen, die Herausforderung durch den Kreml werde notfalls auch mit militärischen Mitteln beantwortet werden? Für den sowjetischen Führer, der keinesfalls ein Kriegsrisiko eingehen wollte, lag da der entscheidende Punkt: Wie weit konnte er sich gegenüber den USA vorwagen, ohne Gefahr zu laufen, in eine bewaffnete Konfrontation mit der anderen Supermacht zu geraten?87

85 Richard Reeves, President Kennedy. Profile of Power, New York-London 1993, S. 169-171, nach einem Brief vom 24. 4. 1989, in dem sich Dean Rusk - außer bezüglich des aus dem Gedächtnis zitierten Schlußsatzes - auf ein Protokoll beruft. Die Auslassungen in eckiger Klammer wurden von Reeves übernommen.

86 Doveritel'naja informacija, a.a.O., Bl. 120.

87 Die geradezu euphorische Überzeugung, daß sich der Sozialismus unaufhaltsam ausbreite, wäh- 
In den zurückliegenden Monaten hatte der amerikanische Präsident ständig sein überragendes Interesse an einer Übereinkunft mit der UdSSR betont. Chruschtschow hatte das als politische Bedürftigkeit gedeutet: Kennedy schien auf ein Einvernehmen unbedingt angewiesen zu sein. Die damit verbundenen Erklärungen, daß er seine Positionen verteidigen werde, falls ihn der Kreml unter Druck setze, hielt der sowjetische Führer für Pflichtübungen, die kaum ernstzunehmen seien. ${ }^{88}$ Die Äußerungen des Präsidenten in Wien schienen das zu bestätigen. Der starke Akzent, mit dem dieser den Wunsch nach Verständigung betonte, beeindruckte den Kremlchef weit mehr als das Argument, die amerikanische Position in Berlin sei der Angelpunkt der gesamten Europa- und Bündnispolitik und werde mit aller Entschlossenheit verteidigt werden. ${ }^{89}$ Dieses Engagement wurde bloßem Prestigebedürfnis zugeschrieben, hinter dem kein wirklich wichtiges Interesse der USA stehe. 90 Kennedys Bezugnahme auf Eisenhowers Äußerung, daß die Lage in Berlin „anomal“ sei, und sein zustimmender Kommentar, die dortige Situation sei tatsächlich „unbefriedigend“, wurden als ausdrückliches Eingeständnis aufgefaßt, daß es in der Stadt zu fundamentalen Veränderungen kommen müsse - und die konnten nach sowjetischer Ansicht nur in einer Erfüllung der gestellten Forderungen bestehen. ${ }^{91}$

Chruschtschow glaubte darüber hinaus, seinen Widerpart in die Defensive gedrängt zu haben. Das - von ihm bei der allgemeinen Diskussion des Ost-WestVerhältnisses geäußerte und mit dem gesetzmäßigen Trend zum Sozialismus begründete - Verlangen nach einseitigen, offensiven Veränderungen hatte ein, wie es schien, nur schwaches Plädoyer für die Wahrung des Status quo hervorgerufen. Der bloße Wunsch nach einer Übereinkunft über die wechselseitige Respektierung des bestehenden Zustandes erschien vor dem Hintergrund von Dulles' und Eisenhowers „Politik der Stärke“, die das „Zurückrollen des Kommunismus“ auf ihre Fahnen geschrieben hatte, als Rückzug eines in die Enge getriebenen Gegners, der um Schonung seines Besitzes bat. Der Kremlchef sah darin - ebenso wie in dem Wunsch nach Aufschub der strittigen Regelungen - nur den hilflosen Versuch, die herannahende Niederlage abzuwenden. Aus Kennedys offen zum Ausdruck gebrachter Sorge, das sozialistische Lager könnte westlich orientierte Länder bedrängen und das internationale Kräfteverhältnis zu seinen Gunsten verändern, schöpfte er die Gewißheit, daß seine Annahme zutraf. ${ }^{92}$ Zudem sah er in der

rend sich die „allgemeine Krise des Kapitalismus“ fortlaufend verschärfe, machte Chruščëv nicht für die Gefahren blind, die der UdSSR im Kriegsfalle drohten. Der Zerfall des Kolonialsystems untergrabe zwar die Grundlagen des Kapitalismus, und die Zeit sei nicht mehr fern, da der Sozialismus „,in der entscheidenden Sphäre der menschlichen Tätigkeit, in der materiellen Produktion“, die Führung übernehme und den - als „Imperialismus“ bezeichneten und als letztlich „vernachlässigenswerte Größe“ eingeschätzten - Westen besiege, doch verfüge dieser mit seiner „mächtigen Militärmaschine“ noch über „große Macht“" (N. S. Chruščëv, Za novye pobedy, a.a.O.).

88 A. Fursenko/T. Naftali, a.a.O., S. 116-128, insbes. S. 125.

89 Memorandum of Conversation between Kennedy and Khrushchev, 4. 6. 1961 (1), FRUS 1961-63, Vol. V [S. 15-20 von 25].

90 Doveritel'naja informacija, a.a.O., Bl. 114.

91 Das ergibt sich aus dem Vergleich zwischen dem ausführlichen amerikanischen Protokoll (Memorandum of Conversation between Kennedy and Khrushchev, 4. 6. 1961, FRUS 1961-63, Bd. V: Soviet Union, http://www.state.gov/www/about_state/history/vol_v/86_89.html, S. 16f.) mit der auswertenden sowjetischen Kurzwiedergabe (Doveritel'naja informacija, a.a.O., Bl. 114).

92 Memorandum of Conversation between Kennedy and Khrushchev, 3. 6. 1961, FRUS 1961-63, 
Übernahme der Rede von der „friedlichen Koexistenz“ durch den Präsidenten die Bereitschaft zu grundlegendem Umdenken, namentlich zur Anerkennung der Zweistaatlichkeit in Deutschland. ${ }^{33}$ Zugleich war er sich freilich bewußt, daß sein Gegenüber mit dem Umdenken vielfach andere Ideen verband als er. ${ }^{94}$ Dessen ungeachtet, verbuchte er es als entscheidenden Sieg, daß Kennedy mit der These vom absteigenden Kapitalismus und aufsteigenden Kommunismus einverstanden zu sein schien. ${ }^{95}$ Demnach akzeptierte der erste Mann der USA die Situationseinschätzung des Kreml als Geschäftsgrundlage der wechselseitigen Beziehungen.

Kennedy hatte sich in den Augen Chruschtschows als „unerfahrener, vielleicht gar unreifer Mensch“ erwiesen, der freilich im Vergleich zu Eisenhower einen weiten politischen Horizont hatte. ${ }^{96}$ Der Eindruck von Unsicherheit und Nachgiebigkeit erklärt sich nicht zuletzt auch dadurch, daß der Präsident seinen Gesprächspartner unter anderen mit verbalen Freundlichkeiten und sogar mittels Einräumung eigener Fehler dazu bewegen wollte, seinerseits politische Korrekturen nicht zu scheuen. Das galt etwas, als er sich voller Bewunderung über das ökonomische Wachstum der UdSSR äußerte, sich von Dulles' Ziel einer Beseitigung des Kommunismus distanzierte und darauf verzichtete, die bisherige amerikanische Politik zu verteidigen. Das leistete der Wahrnehmung Vorschub, an der Spitze der USA stehe ein Mann, der die „Interessen seiner Klasse“ nicht konsequent $\mathrm{zu}$ vertreten wisse und dem Moskauer Konzept der „friedlichen Koexistenz" nichts entgegenzusetzen habe. Die Bemerkung des Präsidenten, mit der Landung auf Kuba habe er einen schweren Fehler gemacht, wurde nicht in der gemeinten Weise als Plädoyer für eine durchgängige wechselseitige Achtung des Status quo, sondern als das Eingeständnis eigener Unfähigkeit aufgefaßt. Der späteren Erinnerung zufolge, amüsierte sich Chruschtschow innerlich über die anachronistischen Auffassungen, die Kennedy vertrat, und die Widersprüche, in die er sich in den Fragen der "friedlichen Koexistenz" verwickelte. 97 Nach dem Zeugnis seines Dolmetschers urteilte er geringschätzig über sein amerikanisches Gegenüber. ${ }^{98}$

Der Kremlchef gestand dem Präsidenten zu, als „in der Politik [noch] unbekannter Mensch" bis an die Grenze dessen gegangen zu sein, was er sich innenpolitisch leisten konnte. Er habe aber nicht den Mut gehabt, diese Grenze zu überschreiten (d.h. den sowjetischen Forderungen zu entsprechen). Denn damit hätte er sich dem Vorwurf der Feigheit (gegenüber der UdSSR) ausgesetzt. Dazu habe

Bd. V: Soviet Union, http://www.state.gov/www/about_state/history/vol_v/80_85.html, S. 8-10, $14 \mathrm{f} ., 17 \mathrm{f} ., 21$.

93 Memuary Nikity Sergeeviča Chruščëva, in: Voprosy istorii, 10/1993, S. 63.

94 Ebd., S. 64.

95 G. M. Kornienko, Upuščënnaja vozmožnost'. Vstreča N. S. Chruščëva i Dž. Kennedi v Vene v 1961g., in: Novaja i novejšaja istorija, 2/1992, S. 98.

96 O. Trojanovskij, a.a.O., S. 234. Zu dieser Angabe, die durch weitere Hinweise bestätigt erscheint, steht die Aussage des Sohnes von Chruščěv in Widerspruch, daß sein Vater Kennedy als einen zwar jungen, aber durchaus alerten Gegner eingeschätzt habe (Sergej Chruščëv, Roždenie sverchderžavy. Kniga ob otce, Moskau 2000, S. 391). Es ist zu vermuten, daß in Sergej Chruščëvs Erinnerung das Bild haften geblieben ist, das sein Vater in der folgenden Zeit vom amerikanischen Präsidenten gewonnen hat.

97 Memuary, a.a.O., S. 65.

98 V. Suchodrev, a.a.O., S. 139. 
er sich außerstande gesehen, weil sein Gewicht „allzu leicht sowohl bei den Republikanern als auch bei den Demokraten“ sei. Das wäre bei Dulles anders gewesen, dem man wegen seiner politischen Statur diesen Vorwurf nicht hätte machen können. ${ }^{99}$ Kennedy selbst schien ihm diese Einschätzung zu bestätigen, als er dem Schwiegersohn Chruschtschows in einem Interview erklärte, man würde ihn ins Gefängnis werfen, wenn er die Forderungen der UdSSR annähme. Der Kremlchef entnahm dieser Mitteilung, der Präsident halte das Moskauer Verlangen an sich für vernünftig und akzeptabel und werde nur durch die Umstände an der Zustimmung gehindert. 100

Das alles hieß freilich nicht, daß Chruschtschow ein einfaches Spiel mit den USA vor sich sah. Ein schwacher Präsident, dessen Verhalten von anderen, schwer zu fassenden Kräften abhing, war ein unberechenbares Gegenüber. Damit erschienen völlig unkalkulierbare Entwicklungen möglich. Großen Einfluß auf Kennedys Politik schrieb der sowjetische Führer vor allem dem - als chaotisches Gremium eingeschätzten - Senat zu. Man müsse dort mit allen Reaktionen rechnen. Auch die Möglichkeit des Krieges lasse sich nicht ausschließen. ${ }^{101} \mathrm{Zu}$ diesen Überlegungen paßt wenig die gleichzeitig geäußerte Ansicht, der zufolge es gleichgültig war, wer an der Spitze der anderen Supermacht stand. Ob es sich nun um Eisenhower, Kennedy oder irgendeinen anderen handele - entscheidend sei allein, daß sie alle ohne Unterschied „Diener des Monopolkapitals“ seien. Nur im Charakter und Auftreten gebe es Verschiedenheiten. ${ }^{102}$

In den Unterredungen mit Kennedy folgte Chruschtschow der vorher festgelegten Maxime, den Druck so stark wie möglich zu erhöhen. Er konnte zwar die amerikanische Position nicht erschüttern, sah sich aber in der Überzeugung bestärkt, auf dem richtigen Weg zu sein, und schickte sich daher an, den Berlin-Konflikt weiter zu eskalieren. Das war genau das Gegenteil dessen, was sich der amerikanische Präsident erhofft hatte. Dazu hatte er freilich selbst beigetragen. Er wußte von den Ausführungen des Kremlchefs über das objektiv-unerbittliche Feindverhältnis zwischen Ost und West, die in Washington Aufsehen erregt hatten, ${ }^{103}$ glaubte aber, seinen Gesprächspartner durch verbales Entgegenkommen zu seinen Vorstellungen eines vernünftigen Umgangs miteinander bekehren zu können. Er verkannte, wie man in Moskau Aussagen des „Klassenfeindes“ interpretierte, und gab dadurch Anlaß zu einer falschen Wahrnehmung seiner Absichten. Umgekehrt sah Chruschtschow nicht, daß er mit Pressionen vorhandene Bereitschaft zu Konzessionen erstickte und den Willen zur Abwehr weckte. Er sah der Konfrontation mit den USA entgegen, war sich aber nicht über die Härte des zu erwartenden Widerstandes im klaren.

\footnotetext{
99 Chruščëvs Ausführungen vor dem Politischen Konsultativkomitee des Warschauer Pakts in Moskau am 4. 8. 1961, wiedergegeben in: Novaja i novejšaja istorija, 2/1999, S. 69.

100 Ebd., S. 75.

101 Chruščëvs Ausführungen am 4. 8. 1961, a.a.O., S. 68 f.

102 Ebd., S. 68; Memuary, a.a.O., S. 62 f.

103 Current Intelligence Weekly Review, 26. 1. 1961: Part III. Notes and Comments (Khrushchev Speech on Moscow Meeting of World Communist Leaders), in: FRUS 1961-1963, Bd. V: Soviet Union, http://www.state.gov/www/about_state/history/vol_v/10_19.html, S.6-8. Der Bericht bezog sich auf N. S. Chruščèv, Za novye pobedy, a.a.O.
} 